IZA DP No. 9773

If You Don't Snooze You Lose:

Evidence on Health and Weight

Osea Giuntella

Fabrizio Mazzonna

February 2016 


\title{
If You Don't Snooze You Lose: Evidence on Health and Weight
}

\author{
Osea Giuntella \\ University of Oxford \\ and IZA
}

Fabrizio Mazzonna

Università della Svizzera Italiana (USI)

Discussion Paper No. 9773

February 2016

\author{
IZA \\ P.O. Box 7240 \\ 53072 Bonn \\ Germany \\ Phone: +49-228-3894-0 \\ Fax: +49-228-3894-180 \\ E-mail: iza@iza.org
}

\begin{abstract}
Any opinions expressed here are those of the author(s) and not those of IZA. Research published in this series may include views on policy, but the institute itself takes no institutional policy positions. The IZA research network is committed to the IZA Guiding Principles of Research Integrity.

The Institute for the Study of Labor (IZA) in Bonn is a local and virtual international research center and a place of communication between science, politics and business. IZA is an independent nonprofit organization supported by Deutsche Post Foundation. The center is associated with the University of Bonn and offers a stimulating research environment through its international network, workshops and conferences, data service, project support, research visits and doctoral program. IZA engages in (i) original and internationally competitive research in all fields of labor economics, (ii) development of policy concepts, and (iii) dissemination of research results and concepts to the interested public.
\end{abstract}

IZA Discussion Papers often represent preliminary work and are circulated to encourage discussion. Citation of such a paper should account for its provisional character. A revised version may be available directly from the author. 


\section{ABSTRACT}

\section{If You Don't Snooze You Lose: Evidence on Health and Weight ${ }^{*}$}

Most economic models consider sleeping as a pre-determined and homogeneous constraint on individuals' time allocation neglecting its potential effects on health and human capital. Several medical studies provide evidence of important associations between sleep deprivation and health outcomes suggesting a large impact on health care systems and individual productivity. Yet, there is little causal analysis of the effects of sleep duration. This paper uses a spatial regression discontinuity design to identify the effects of sleep on health status, weight, and cognitive abilities. Our results suggest that delaying morning work schedules and school start times may have non-negligible effects on health.

JEL Classification: I12, J22, C31

Keywords: health, obesity, sleep deprivation, time use, regression discontinuity

Corresponding author:

Osea Giuntella

University of Oxford

Nuffield College

Blavatnik School of Government

1 New Road

OX11NF, Oxford, Oxfordshire

United Kingdom

E-mail: osea.giuntella@nuffield.ox.ac.uk

\footnotetext{
* We are thankful to John Cawley, Martin Gaynor, Daniel Hamermesh, Kevin Lang, Raphael Parchet, Daniele Paserman, Franco Peracchi, Climent Quintana-Domeque, Judit Vall-Castello, Randall Walsh, and Nicolas Ziebarth for their comments and suggestions. We are also grateful to participants at workshops and seminars at the University of Lausanne, Universidad de Navarra, University of Oxford, University of Pittsburgh, Universitat Pompeu Fabra, Stockholm School of Economics, and the University of Warwick.
} 
IZA Discussion Paper No. 9760

February 2016

\section{NON-TECHNICAL SUMMARY}

Sleep deprivation is increasingly recognized as a major public health challenge and one of the most prevalent high-risk behaviours in modern society. It therefore follows that increasing the awareness of the negative effects of sleep deprivation is crucial for the design of policies aimed at reducing the cognitive decline associated with ageing. However, the causal evidence on the effects of sleep deprivation has been so far limited.

This paper exploits a quasi-natural experiment provided by the relationship between circadian rhythms and sleep behaviour to study the effects of sleep deprivation on health and cognitive skills. We focus on the effects of insufficient sleep on general health status and obesity in the US. In particular, we exploit the fact that on the eastern side of a time-zone boundary, sunset occurs an hour later than on the opposite side of the border. As the production of melatonin is affected by environmental light, we show that individuals living in counties on the eastern side of a time zone boundary tend to go to bed later than individuals living in nearby counties on the opposite side of the time zone boundary. However, individuals who have to wake up early in the morning because of their working schedules or because of children's school start times cannot compensate in the morning; thus a later bedtime results in less sleep. Using this variation, we find that sleep deprivation increases the likelihood of reporting poor health status and the incidence of obesity. We also find evidence that sleep duration increases the risk of cognitive impairment.

Our findings suggest that higher propensity to eat late in the evening, regardless of the time spent eating earlier in the day, as well as higher likelihood of dining out and lower likelihood of engaging in moderate or intense physical activity contribute to explain the effects of sleep deprivation on obesity and health status.

These results highlight the importance of developing a public awareness about the negative effect of sleep deprivation and suggest that reshaping social schedules in ways that promote sleeping may have non-trivial effects on health. Many individuals suffer from a misalignment between social and biological time. While working schedules respond to economic incentives and returns to coordination, their costs in terms of negative effects on health and human capital should not be underestimated. Sleep education programs should become a central part of any program aiming at reducing obesity and weight gain in populations at risk. 


\section{Introduction}

Time is one of our scarcest resources, and economists have long been interested in the analysis of individuals' time use. However, while we spend approximately one-third of our time sleeping, and despite the evidence of important heterogeneity in sleeping in the population, the sources of these differences and the factors affecting sleep duration decisions are not well understood. Most economic models analyzing time allocation regard sleeping as a pre-determined and homogeneous constraint on individuals' time allocation. Notable exceptions are the seminal paper by Biddle and Hamermesh (1990) analyzing the relationship between economic incentives and sleep duration and subsequent studies analyzing the determinants of sleep duration (Ásgeirsdóttir and Ólafsson, 2015; Brochu et al., 2012; Szalontai, 2006). ${ }^{1}$ If sleep deprivation has causal effects on health, the sleep deprivation epidemic may have substantial costs for the health care system. Furthermore, through its effects on health capital and cognitive skills (Giuntella et al., 2015), sleep deprivation can also have important effects on human capital and productivity (Gibson and Shrader, 2014). Sleep deprivation has been associated with a higher likelihood of medical errors and worse performance among doctors and nurses (Weinger and Ancoli-Israel, 2002). However, we know relatively little about the health and economic consequences of insufficient sleep. In particular, while there is a wide set of studies providing evidence of an important association between sleeping and negative health outcomes, it is unclear whether sleep duration is a cause or a marker of poor health (Cappuccio et al., 2010). The goal of this paper is to analyze the causal effects of sleep duration on health, shedding light on the mechanisms underlying this relationship and investigating how sleep duration is affected by social constructs (e.g., work schedules, school start times). To identify the effects of sleep duration we adopt a Spatial Regression Discontinuity Design (RDD).

Insufficient sleep is associated with a higher incidence of chronic diseases (i.e. hypertension, diabetes), cancer, depression and early mortality (see Cappuccio et al., 2010, for a systematic review). Moreover, sleep duration may be an important regulator of body weight and metabolism (Taheri et al., 2004; Markwald et al., 2013). Insufficient sleep has been also linked to motor vehicle crashes (Lyznicki et al., 1998; Barger et al., 2005). Furthermore, anecdotical evidence suggests that sleep loss played an important role in major industrial disasters (e.g., the Chernobil accident). ${ }^{2}$

Despite the increased attention on sleep deprivation, some estimates suggest that in many countries, individuals are sleeping as much as two hours less per night than did their ancestors one hundred years ago (Roenneberg, 2013). Figure 1 illustrates the dramatic shift in the share of individuals reporting less than 6 hours of sleep between 1942 and 1990. A survey conducted in 2013 by the U.S. National Sleep Foundation found that Americans are more sleep-starved

\footnotetext{
${ }^{1}$ The discussion on the economics of sleeping began earlier in the 1970s with an article by El Hodiri (1973), continued by Bergstrom (1976) and extended by Hoffman (1977). However, Biddle and Hamermesh (1990) were the first to formalize the analysis of the sleeping decision and econometrically analyze its relationship with economic incentives.

${ }^{2}$ See http://www.huffingtonpost.com/2013/12/03/sleep-deprivation-accidents-disasters_n_4380349. html.
} 
than their peers abroad, and the Institute of Medicine (2006) estimates that 50-70 million US adults have sleep or wakefulness disorder (Altevogt et al., 2006). Figure 2 shows that during the workweek, individuals tend to sleep significantly less than the recommended 8 hours but with important heterogeneity with respect to education and work schedules. Consistent with previous studies analyzing the relationship between wages, socio-economic status and sleeping time, we find evidence that education is negatively correlated with sleep duration, suggesting a trade-off between sleeping and income (Ásgeirsdóttir and Ólafsson, 2015; Biddle and Hamermesh, 1990). ${ }^{3}$ Furthermore, regardless of the educational group considered, individuals who begin to work later in the morning tend to sleep longer. In light of these trends, in a recent article in Nature, Roenneberg (2013) argues that unnatural sleeping and waking times could be the most prevalent high-risk behavior in modern society and proposes a global human sleep study to restructure work and school schedules in ways that may better suit our biological needs.

The causal evidence on the effects of sleep duration has thus far been limited to laboratory studies. However, experimental studies conducted in the lab offer only a limited understanding of both the determinants and consequences of sleep deprivation (Roenneberg, 2013). Such studies are typically based on people who have been instructed to follow certain sleep patterns (e.g., bedtimes), are not sleeping on their beds, and are affected by laboratory settings (e.g., individuals are often required to sleep with electrodes fastened to their heads). Moreover, most of the experimental evidence focuses on the effects of total sleep deprivation (awake continuously for 1 to 3 days), while few studies evaluate the consequences of chronic partial sleep deprivation (i.e., repeated exposure to sleep durations of less than 6-7 hours per night), a condition that is far more common in reality (Van Dongen et al., 2003b; Spiegel et al., 1999; Dinges et al., 1997).

This paper has two main contributions. First, we explore the importance of work schedules and other social constructs (e.g., school start times) in determining sleep duration. Second, we provide a causal estimate of the effects of sleep duration on health using time-use data that are more likely to capture real-world sleeping habits. In particular, we focus on the effects of insufficient sleep on general health status and weight. Both self-reported health status and excessive weight have been shown to have important effects on individuals' productivity and on health care costs (Cawley, 2015, 2004; Burton et al., 2005). Furthermore, we examine the effects on cognitive impairment.

Our identification strategy exploits the discontinuity in sleep duration that occurs at the boundary of a time zone as a result of the discontinuity in sunset time. In counties lying on the eastern (right) side of a time zone boundary, sunset time occurs an hour later than in nearby counties on the opposite side of the boundary. Because of circadian rhythms, the body reacts to environmental light, producing more melatonin when it becomes darker. This is a gradual process known as entrainment. Thus, because sunset occurs at a later hour, individuals on the eastern side of a time zone boundary will tend to go to bed at a later time. ${ }^{4}$ In addition, as

\footnotetext{
${ }^{3}$ This is true even if we examine the relationship between hourly wages and sleep duration within each educational group.

${ }^{4}$ There is substantial medical evidence indicating how solar cues affect sleep timing (see Roenneberg et al., 2007,
} 
prime-time evening shows air at 10 p.m. Eastern and Pacific, 9 p.m. Central and Mountain, TV programs may also affect bedtime and reduce or reinforce the effect of sunset time (Hamermesh et al., 2008). Note that if people were to compensate by waking up later, solar and TV cues would have no effect on sleep duration. However, because of economic incentives, social schedules, such as working schedules and school start times, are usually less flexible than biological timing. Thus, many individuals are not able to fully compensate in the morning by waking up at a later time.

Figure 3 illustrates the variation in average sunset time across US counties. Within a given time zone, eastern counties have earlier sunset times than do more western counties. At the time zone border, there is a sharp discontinuity between counties on the eastern (right) side of the border (late sunset side) and counties on the western (left) side of the border (early sunset side).

Using data on the average bedtime of Jawbone's sleep trackers users across US counties, publicly available on the Jawbone website ${ }^{5}$, Figure 4 illustrates the clear discontinuity in bedtime at each time zone border. The bottom figure provides a zoom at the north border between the Eastern and the Central time zones. The figure shows that people living in counties on the eastern (left) side of a time zone border go to sleep later than people in neighboring counties on the western (right) side of the time zone boundary. These differences in bedtime give rise to differences in sleep duration across time zone borders because many people cannot fully compensate by sleeping longer in the morning. We show that this is particularly true for workers, because standard office hours are the same across borders, and for parents with children, because they are likely constrained by school start times.

Using data from the American Time Use Survey, we show that employed people living in counties bordering the eastern side of a time zone sleep on average 19 fewer minutes than employed people living in neighboring counties on the opposite side of the border because of the one-hour difference in sunset time. More generally, individuals on the eastern side of a time zone boundary are more likely to be sleep deprived, being more likely to sleep less than 6 hours, less likely to sleep at least 8 hours, and less likely to sleep the recommended 7-8 hours. ${ }^{6}$ The effects are larger among individuals with early working schedules and among individuals with children of school age. We find that TV plays only a limited role in explaining the discontinuities at the border.

The difference in sleep duration across time zone borders gives rise to large differences in the likelihood of being overweight, obese, and in self-reported health. People on the eastern side of

for a review). The daily light-dark cycle governs the so-called circadian rhythms, rhythmic changes in the behavior and the physiology of most species, including humans (e.g., Vitaterna et al., 2001). Studies have found that these circadian rhythms follow an approximately 24-hour cycle and are governed by the suprachiasmatic nucleus (SCN), or internal pacemaker also known as the body's master clock. The SCN synchronizes biological rhythms with environmental light, a process known as "entrainment". When there is less light, the SCN stimulates the production of melatonin, also known as "the hormone of darkness", which in turn promotes sleep in diurnal animals, including humans (Aschoff et al., 1971; Duffy and Wright, 2005; Roenneberg et al., 2007; Roenneberg and Merrow, 2007).

${ }^{5}$ Jawbone is one of the leading producers of wearable devices. The figure was downloaded from the Jawbone blog, https://jawbone.com/blog/circadian-rhythm/. We accessed the data on January 31, 2015

${ }^{6}$ See the recent sleep guidelines from the National Heart, Lung, and Blood Institute http://www.cdc.gov/sleep/ about_sleep/how_much_sleep.htm 
a time zone boundary are $10 \%$ more likely to be overweight, $23 \%$ more likely to be obese, and $30 \%$ more likely to report a poor-health status. It is worth noting that, especially in the case of weight measures, these are the consequences of a long-term-exposure to sleep restrictions. This is confirmed by the evidence of larger effects among older workers (over 40). These findings are consistent with the growing evidence that sleep debt is associated with metabolic and endocrine alterations that have long-term physiopathological consequences (Spiegel et al., 1999; Knutson and Van Cauter, 2008). Furthermore, the magnitude of the effects is comparable with the associations found in epidemiological studies (Moreno et al., 2006; Hasler et al., 2004; Cappuccio et al., 2008) and consistent with previous evidence from animal studies finding large effects of partial sleep deprivation on weight (Knutson et al., 2007). ${ }^{7}$ Finally, using data from the 2000 US Census, we find evidence of a discontinuity in cognitive impairment, suggesting that sleep deprivation may have important effects on cognitive skills.

We then turn to the analysis of the possible mechanisms underlying the relationship between sleeping and health and excessive weight. There are several biological channels through which sleep deprivation may affect individual health, weight gain, and cognitive impairment. First, sleep duration and quality are important predictors of levels of Hemoglobin A1c, an important marker of blood sugar control (Knutson et al., 2006). In addition, insufficient sleep increases the level of chemicals linked with inflammation (Irwin et al., 2006). Furthermore, the medical literature associates sleep deprivation with a reduction of leptin, the so-called "satiety hormone", and with an increase of ghrelin, also known as the "hunger hormone" (Ulukavak et al., 2004). Moreover, behavioral studies show that sleep loss increases the likelihood of gaining excessive weight by increasing the consumption of fats and carbohydrates and by reducing the likelihood of being engaged in moderate or intense physical activity (Greer et al., 2013; Markwald et al., 2013). Sleep deprivation may induce fatigued individuals to eat more- in particular to eat more carbohydrates- to sustain their wakefulness while their exhaustion may simultaneously reduce their physical activity, leading to an increase in weight gain. Finally, there is evidence that sleep deprivation is associated with global decreases in brain activity mediating attention and higherorder cognitive processes (Thomas et al., 2000; Williamson and Feyer, 2000). Consistent with these studies, we find evidence that individuals on the eastern side of the time zone border are more likely to eat late in the evening than their neighbors on the western side of the time zone border, regardless of the number of times or the time spent eating earlier in the day. Those to the east of the border are also more likely to eat out and less likely to engage in physically intensive activities.

Our results are robust to a large battery of robustness checks. First, we show that there is no discontinuity in predetermined characteristics known not to be affected by the treatment (sleeping). In particular, we find that individuals' height does not differ systematically across the time zone border and that there is no evidence of any significant relationship with human capital

\footnotetext{
${ }^{7}$ Moreno et al. (2006) find that among Brazilian truck drivers sleep duration $<8$ h per day was associated with a $24 \%$ greater odds of obesity, while Hasler et al. (2004) find that every extra hour increase of sleep duration was associated with a $50 \%$ reduction in risk of obesity.
} 
indicators at the beginning of the 20th century when time zones had not yet been introduced in the United States. Moreover, by examining population density, home (and rent) values and commuting time, we do not find any evidence of residential sorting across the time zone borders.

Overall, our results suggest that sleeping has important effects on health status and weight. Furthermore, the heterogeneity of our results with respect to occupational and demographic characteristics suggests that sleep duration is importantly affected by social constructs such as working schedules and school start times that could be restructured in ways that may better suit our biological needs. In particular, we find that the differences in sleep duration are driven by workers beginning to work before 8:30am and larger among individuals waking up early to bring children to school. Delaying the start of work after 8:30am would eliminate the differences in sleep duration at the time zone border and, more generally, improve average sleep duration in the US.

Our paper contributes to a small but growing number of studies analyzing the consequences of sleep deprivation. In a recent study, Jin and Ziebarth (2015) study the health effects of Daylight Saving Time (DST) and find that health slightly improves in the short run (4 days) when clocks are set back by one hour in the fall but no evidence of detrimental effects when moving from standard time to DST in the spring. Using a similar strategy, Smith (forthcoming) shows that DST increases fatal crashes. Exploiting the time and geographical variation in sunset time within each time zone, Gibson and Shrader (2014) find that a one-hour increase in average daily sleep increases productivity to a greater extent than does a one-year increase in education. Similarly, Bonke (2012) examines productivity differences between morning and evening chronotypes. Finally, this paper is also related to the studies analyzing the effects of school start times on academic achievement (Carrell et al., 2011; Edwards, 2012; Stewart, 2014) and showing that even small differences in school start times can have large effects on academic outcomes. However, none of these papers exploits the sharp discontinuity at time zone borders or analyzes the medium and long-run health consequences of sleep restrictions.

This paper is organized as follows. In Section 2, we briefly discuss the context. Section 3 describes our identification strategy, the empirical specification and the data used in our analysis. In Section 4, we examine the relationship between sunset time and sleeping and its heterogeneity in the population. Section 5 discusses the main results and the mechanisms underlying our main results. Section 6 illustrates a battery of robustness checks. Concluding remarks are provided in Section 7.

\section{Background: US Time Zones and Solar and TV Cues}

\subsection{US Time-zones}

As shown in Figure 3, the contiguous United States is divided into 4 four main time zones (Eastern, Central, Mountain, and Pacific). The time zones were first introduced in the US in 1883 to regulate railroad traffic. However, even in relatively nearby areas, scheduling was far from 
being uniform at that time (Hamermesh et al., 2008; Winston et al., 2008). The four current U.S. time zones were officially established with the Standard Time Act of 1918, and there have only been minor changes since then, primarily at their boundaries. The Eastern time zone was set -5 hours with respect to Greenwich Mean Time (GMT), and the other three time zones (Central, Mountain and Pacific) differ from that by $-1,-2$, and -3 hours, respectively. It is worth noting that time zone borders do not always coincide with state borders. In 12 of the contiguous US states, different counties follow different time zones.

The introduction of DST was, by contrast, more troublesome. The DST was first adopted in 1918, during World War I, as in other countries as a means to conserving energy. However, because of its unpopularity, it was repealed after the war. The current DST was introduced in 1966 with the Uniform Time Act. Changes to the DST schedule were then made in 1976 and 2007, when DST was extended by 4 weeks. Since 2007, in most of the US, clocks are set one hour ahead in early March, and are set one hour back early in November. However, Arizona has not observed DST since 1967, while Indiana, with the exception of some counties at the border between the Central and Eastern time zones, did not follow DST until 2006.

Since 1918, a few counties petitioned the Department of Transportation for a change in their time zones. Over time there, has been a westward movement of time zone boundaries. While this movement clearly makes the time zone boundary endogenous, as Gibson and Shrader (2014) note, the westward movement of boundaries would have, if anything, negative effects on sleep duration, as counties moving to the eastern side of a time zone boundary would move from early sunset areas to late sunset areas.

\subsection{Timing of Television Programs}

Television networks usually broadcast two separate feeds, namely the "eastern feed" that is aired at the same time in the Eastern and Central time zones and the "western feed" for the Pacific time zone. In the Mountain time zone, networks may broadcast a third feed on a one-hour delay from the Eastern time zone. Television schedules are typically posted in Eastern/Pacific time, and thus, programs are conventionally advertised as "tonight at 9:00/8:00 Central and Mountain". Therefore, in the two middle time zones, television programs start nominally an hour earlier than in the Eastern and Pacific time zones. As Hamermesh et al. (2008) and Winston et al. (2008) note, this practice originated in the 1920s when, because of the radio transmission technology available at the time, broadcasting would be simultaneous in the Central and Eastern time zones and the same program would be received an hour earlier in the Central time zone - while Mountain and Pacific time zones would receive repeats. With the beginning of TV broadcasting, it became customary for the Eastern feed to be delayed by one hour in the Mountain time zone. These differences in the timing of TV shows have persisted over time such that prime time in the two coastal zones runs from $8 \mathrm{pm}$ to $11 \mathrm{pm}$, while in the two middle time zones, it runs from $7 \mathrm{pm}$ until 10pm. As this practice was introduced even before the beginning of TV broadcasting and responded to people's preferences for live performances at desirable times, Hamermesh et al. 
(2008) argue that TV cues can be considered external to agents, while nevertheless affecting their timing, and show that the scheduling of television programs affects timing and bedtime.

While, by construction, sunset occurs an hour later on the eastern side of each time zone border (EC, CM, MP), prime time shows may reinforce or reduce the sunset effect. In particular, prime time shows start nominally an hour later on the eastern side of the time zone boundary between the Central and Eastern time zones, an hour earlier on the eastern side of the time zone boundary between Mountain and Pacific, and at the same time along the counties bordering with the time zone border between Central and Mountain time zones. ${ }^{8}$

Thus, we expect that if TV schedules affect individual bedtime, the discontinuity in bedtime should be larger along the Central-Eastern time zone border and smaller along the PacificMountain time zone border. We examine the role of TV schedules in Section 4.3.

\section{Identification Strategy and Empirical Specification}

\subsection{Identification Strategy}

The empirical analysis in this paper focuses on the effect of sleep deprivation on health (overweight, obesity, and self-reported health). A simple comparison of people with different sleeping behavior would not allow us to identify the causal effect of sleep deprivation on health because of both reverse causality and several potential confounding factors (e.g., stress, type of occupation).

In this paper, we address the identification problem by using a spatial RDD that contrasts the sleeping behavior of residents on either side of the three main US time zone borders (EasternCentral, Central-Mountain and Mountain-Pacific). The intuition is that, because of the one-hour difference in sunset time and because of circadian rhythms, individuals in counties bordering on the eastern side of the time zone border go to bed later than people in neighboring counties on the opposite side of the border. However, these individuals are otherwise very similar, as we document in Section 3.3. Figure 5 illustrates the sharp discontinuity in sunset time at the border, aggregating the average sunset time of the US counties based on the distance (in miles) from the closest time zone border. This discontinuity is mirrored by the observed difference in average bedtime at the time zone border (see Figure 4). In Section 4, we show that this difference in average bedtime generates significant differences in sleeping behavior, as people on the eastern border of a time zone boundary do not completely compensate for this difference by waking up later. This is especially true for workers who must cope with standard office hours that are approximately the same across borders (office hours usually begin at 8am or 9am) and for people with children of school age. As we noted above, the discontinuity in bedtime may be more (less) marked on the Eastern-Central (Pacific-Mountain) border if individuals' bedtimes are affected by TV cues.

\footnotetext{
${ }^{8}$ Note that in practice, we do not include Arkansas and Idaho as after imposing our sample restrictions we are left with no observations for these two states in the in the ATUS sample.
} 
Our identification strategy exploits this spatial discontinuity in sleep duration. If we focus on a reasonably small bandwidth around each time zone and if we expect a causal relationship between sleep duration and health, the observed sleeping difference should generate differences in health (here measured using weight and self-reported health) that should not be confounded by other observable and unobservable characteristics. For simplicity, we assume that the relationship between sleep duration and health is linear. Under this assumption, our estimation strategy allows us to estimate the effect of sleeping duration on health. We discuss and test for the presence of non-linear effects in the robustness checks. Furthermore, we consider non-linear metrics of sleep duration in the empirical analysis.

A natural concern is that daylight exposure may vary across the time zone border and thus violate the exclusion restriction. For instance, sunlight exposure increases the production of vitamin D, which is usually associated with mood and depression (e.g., Kjærgaard et al., 2012). As we control for latitude and compare nearby counties, two locations at the same latitude but on the opposite side of a time zone boundary will experience the same daylight duration and differ only in the timing of daylight. ${ }^{9}$ Thus, sorting on daylight duration would not bias our estimates because daylight duration is fixed. Although the timing of daylight may affect individuals' exposure to environmental light during their waking activities, it is worth noting that, if there is a difference in actual daylight exposure across the time zone border, this should advantage individuals living on the eastern side of the time zone border who would be exposed to a later sunset time. A related concern is that sunset time may directly affect weight not only through the effects on sleep but also through its effects on daylight exposure and physical activity. However, previous studies suggest that, if anything, light exposure would increase physical activity (Roenneberg et al., 2012; Wolff and Makino, 2012). Thus, the difference in daylight exposure might introduce a downward bias in the estimated effect of sleep duration on health and weight.

It is worth noting that the health differences across bordering counties, particularly in the case of weight, are likely to be the result of long-term exposure to chronic and partial "sleep deprivation" as supported by recent experimental studies providing evidence of cumulative effects of short sleep duration (Van Dongen et al., 2003a; Spiegel et al., 1999). In other words, what we measure when analyzing the effect of a one-hour increase in sleep duration is not the effect of a one-hour difference in sleep duration in the night preceding the survey interview but rather the average effect of a long-term exposure to a one-hour difference in sleep that depends on the time spent in a given location.Indeed, we show that this effect is larger for older than for younger people, as older people have been exposed for a longer time period than younger people to differential sunset time. Moreover, if people often change their residence, it is likely that the estimated effect on health represents only a lower bound of the true effect, unless healthier individuals systematically move from the eastern to the western side of each time zone border. In the

\footnotetext{
${ }^{9}$ In the robustness checks, we consider the potential impact of geographical and seasonal heterogeneity in daylight duration.
} 
robustness checks reported in Section 6, we implement a large battery of tests for residential sorting across bordering counties and find no evidence of it. In particular, we test for the presence of discontinuities in pre-determined characteristics for which we have data -namely respondents' height and literacy rates in 1900- and for discontinuities in population density, home (and rent) values and commuting time.

From an econometric perspective, the general idea in an RD design is that the probability of receiving a treatment (an additional hour of sleep) is a discontinuous function of a continuous treatment-determining variable (sunset time). However, the treatment in our case does not change from 0 to 1 at the time zone border. Our running variable, $D$, is the distance (in miles) from the time zone border. Distance is positive for counties on the eastern side of the border $(D>0)$ and negative for counties on the western side $(D<0)$. Let $E_{e}(H) \equiv \lim _{\epsilon \rightarrow 0} E(H \mid D=0+\epsilon)$ and $E_{w}(H) \equiv \lim _{\epsilon \rightarrow 0} E(H \mid D=0-\epsilon)$ define the expectation for the two sides of our observed health outcomes when approaching the border from East (e) and West (w).

If we assume that there are no other unobservable characteristics that change at the border, contrasting the health outcome, $H$, at the time zone border, $E_{e}(H)-E_{w}(H)$, measures the effect of the sleeping differences at the border generated by the time zone change. This identification is clearly fuzzy because it does not generate a sharp discontinuity in sleeping hours. In fact, people may partially offset the effect of the different sunset time by adjusting their sleeping or waking time. This means that we need to use a 2SLS strategy that "inflates" the reducedform effect, $E_{e}(H)-E_{w}(H)$, taking into account the sleep duration $(S)$ difference at the border, $E_{e}(S)-E_{w}(S)$. Therefore, our fuzzy spatial RDD may be seen as a Wald estimator around the time zone discontinuity:

$$
\tau_{R D D}=\frac{E_{e}(H)-E_{w}(H)}{E_{e}(S)-E_{w}(S)} .
$$

\subsection{Empirical Specification}

Specifically, we exploit the geographical variation in sunset time at the border, estimating the following two equations:

$$
\begin{gathered}
H_{i c}=\alpha_{0}+\alpha_{1} S_{i c}+\alpha_{2} D_{c}+\alpha_{3} D_{c} * E B_{c}+X_{i c}^{\prime} \alpha_{4}+C_{c}^{\prime} \alpha_{5}+I_{i c}^{\prime} \alpha_{6}+u_{i c} \\
S_{i c}=\gamma_{0}+\gamma_{1} E B_{c}+\gamma_{2} D_{c}+\gamma_{3} D_{c} * E B_{c}+X_{i c}^{\prime} \gamma_{4}+C_{c}^{\prime} \gamma_{5}+I_{i c}^{\prime} \gamma_{6}+v_{i c}
\end{gathered}
$$

where $S_{i c}$ is the sleep duration of individual $i$ in county $c ; E B_{c}$ is an indicator for the county being on the eastern side of a time zone boundary; $D_{c}$ is the distance to the time zone boundary "running variable" (or forcing variable) using the county centroid as an individual's location; the vector $X_{i c}$ contains standard socio-demographic characteristics such as age, sex, race, education, marital status, and number of children; and $C_{c}$ are county characteristics, such as region (Northeast, Midwest, South, West), latitude and longitude and whether the respondent lives in a very 
large county. ${ }^{10}$ We also account for interview characteristics that might affect an individual's sleeping behavior $\left(I_{i c}\right)$, such as interview month and year, a dummy that controls for the adoption of DST in county $c$, and two dummies that control for whether the interview was conducted during a public holiday or over the weekend. We control for the running variable using a local linear regression approach with a varied slope on either side of the cutoff. As robustness check, we also use (and compare) higher polynomial orders to control for the distance from the border (see Section 6).

Substituting the treatment equation into the outcome equation yields the reduced-form equation:

$$
H_{i c s}=\beta_{0}+\beta_{1} E B_{c}+\beta_{2} D_{c}+\beta_{3} D_{c} * E B_{c}+X_{i c}^{\prime} \beta_{4}+C_{c}^{\prime} \beta_{5}+I_{i c}^{\prime} \beta_{6}+\epsilon_{i c s}
$$

where $\beta_{1}=\alpha_{1} * \gamma_{1}$. Therefore, we can estimate the parameter of interest, $\alpha_{1}$, as the ratio between the reduced-form coefficients, $\beta_{1} / \gamma_{1}$, via 2SLS. Standard errors are robust and clustered according to the distance from each time zone border (10-mile groups).

As mentioned above, the main assumption underlying our identification strategy is that the observed differences in health at the time zone border only reflect differences in sleeping behavior generated by solar cues or by other exogenous cues (e.g., TV schedules) that may affect sleep duration.

Again, the underlying idea is that individuals in nearby counties are similar on other characteristics. As for any identification assumption, this is directly untestable. However, using both individual- and county-level data, Table 1 illustrates that a large set of observable characteristics is well balanced in a relatively small bandwidth from the time zone boundary (within 250 miles). We use a bandwidth of 250 miles to ensure that areas on the eastern/western side of a time zone boundary do not overlap while maximizing our identification power. However, in Section 4, we show that the effect of the different sunset time at the border on sleep duration is robust to the inclusion of state fixed effects and to the restriction of our analysis to a very narrow bandwidth around the time zone boundaries (100 miles).

Finally, the heterogeneity of our findings with respect to employment status, family composition, work schedule and type of occupation is consistent with our hypothesis that employed people, parents with children, and individuals with early work schedules are less likely to fully adjust their sleeping behavior in response to the different sunset time on the two sides of the border (see Section 4).

\subsection{Data and descriptive statistics}

In this paper, we use data from the American Time Use Survey (ATUS) conducted by the U.S. Bureau of Labor Statistics (BLS) since 2003. Our sample covers the years 2003-2013. The ATUS sample is drawn from the exiting sample of Current Population Survey (CPS) participants. The

\footnotetext{
${ }^{10}$ We control for the fact that in the case of very large counties, the distance based on the centroid might be a very noisy approximation of the individual sunset time.
} 
respondents are asked to complete a detailed time use diary of their previous day that includes information on time spent sleeping and eating. In 2003, 20,720 individuals participated in the survey. Since 2004, on average, more than 1,100 individuals have participated in the survey each month since 2004, and the last available survey year is 2013. This yields a total sample of approximately 148,000 individuals. In our analysis, we restrict attention to individuals in the labor force (both employed and unemployed) ${ }^{11}$ living within 250 miles of each time zone boundary (Pacific-Mountain, Mountain-Central, Central-Eastern). This is achieved by merging the ATUS individuals with CPS data to obtain information on the county of residence of ATUS respondents. Unfortunately, CPS does not release county information for individuals living in counties with fewer than 100,000 residents; thus, we can match only $44 \%$ of the sample. We further restrict our sample to people aged 18 to 55 years to avoid the confounding effect of retirement and the selection issue that might arise focusing on high-school age workers. We also limit the analysis to individuals who sleep between 2 and 16 hours per night. ${ }^{12}$ After imposing these restrictions, the sample comprises 18,639 individuals, of whom 16,557 were employed. Employment status was determined on the basis of responses to a series of questions relating to their activities during the preceding week. We also have information on whether the wake-up day it's a workday for someone.

The variable of main interest is sleep duration. We count only night sleeping by excluding naps (sleep starting and finishing between $7 \mathrm{am}$ and $7 \mathrm{pm}$ ). ${ }^{13}$ We also consider alternative measures of sleep duration such as indicators for reported sleep of at least 8 hours (or less than 6), being asleep at $11 \mathrm{pm}$ or being awake at $7.30 \mathrm{am}$. These metrics are often used in sleep studies (Cappuccio et al., 2010).

We evaluate the effect of sleep duration on overweight status (BMI > 25), obesity (BMI> 30) and the likelihood of reporting poor health status, defined as reporting poor or fair health status, as is common in the literature using metrics of self-reported health status. Unfortunately, information on these health outcomes is not available in all survey years. In particular, questions on self-reported health status are only available since 2006, while information on body weight is available in the Eating Module included in the survey in the 2006-2009 waves.

In our analysis, we include several socio-demographic controls, age, sex, education, race, marital status and number of children, that might affect individuals' sleeping behavior. Moreover, we use geographic controls, such as census region and latitude, to avoid other geographical factors confounding our analysis at the time zone border.

Table 1 reports summary statistics for the variables of interest for each side of the border for our main sample that includes only employed people. However, there is no significant difference in the likelihood of being employed between individuals living on opposite sides of the time

\footnotetext{
${ }^{11}$ We exclude people not in the labor force because this category includes individuals disabled due to an illness lasting at least 6 months.

${ }^{12}$ Those so excluded are mostly individuals who did not report any sleep duration. However, including those sleeping less than 2 hours does not substantially affect the results, as they represent approximately $1 \%$ of the entire sample.

${ }^{13}$ The results are unchanged when including naps in the main variable (see Table A.1).
} 
zone boundary (coef., -0.010; std. err., 0.013). Columns 1 and 2 report summary statistics for individual living on the western (early sunset) and the eastern (late sunset) side of one of the three main time zone borders, respectively. Note that approximately $50 \%$ of the ATUS sample is interviewed over the weekend, and thus the average sleep duration in the sample is longer than that observed during the workweek (see Figure 6). Furthermore, it is worth noting that self-reported sleep tends to overestimate objective measures of sleep duration (Lauderdale et al., 2008). In particular, Basner et al. (2007) note that the values for sleep time may overestimate actual sleep because the ATUS Activity Lexicon includes transition states (e.g, falling asleep).

By construction, there is a large and significant difference in average sunset time between respondents living across the time zone border. This difference is correlated with individual sleeping behavior. Respondents living in early-sunset counties have significantly higher sleep duration. They sleep on average 10 minutes longer and have a $4 \%$ higher probability of sleeping for at least 8 hours. This difference arises from the fact that they go to sleep later, but they do not compensate by waking up later (compare awake at midnight and awake at $7.30 \mathrm{am}$ ).

Figure 7 confirms the presence of an even larger discontinuity in sleep duration at the time zone border for employed respondents of approximately 20 minutes. In particular, each point represents the sample mean of sleep duration for a group of counties aggregated according to the distance to the border. ${ }^{14}$ For purely descriptive purposes, the fitted lines are based on a linear fit within 250 miles from the border on either side. Restricting the analysis to employed individuals living within 250 miles from the border leaves us with a sample of 16,557 observations.

Conversely, the other individual characteristics are well balanced across the two groups. The only significant coefficient among the covariates is the proportion of blacks (see column 3 ). The higher presence of blacks on the eastern side of the time zone boundary mostly reflects the high density of African Americans in the Eastern time zone in the South. ${ }^{15}$ When including a control for latitude (or Census region), this difference disappears.

\section{Circadian Rhythms, Social Schedules, and Sleep Duration}

\subsection{First-Stage: Sleep Duration across Time Zone Boundaries}

Table 2 illustrates the estimated effect of being on the eastern side of a time zone boundary on sleep duration, as described in equation (2). In column 1, we show that our baseline estimates coincide with the unconditional evidence reported in Figure 7. After controlling for a large set of socio-demographic, geographical and interview characteristics, the estimated effect of being on the eastern side of the boundary ("late sunset border") is approximately 19 minutes, reducing sleep duration by 0.2 standard deviations (see Table 1). The other three columns confirm the

\footnotetext{
${ }^{14}$ We exclude from the graph Arizona and Indiana that did not adopt DST throughout the entire period under study (see Section 1.2). When including these states, the figure is substantially unchanged, but the confidence intervals become wider. However, we include Arizona and Indiana in the main analysis.

${ }^{15}$ Note that we include controls for race, region and latitude in all of our estimates.
} 
robustness of our findings to the inclusion of additional controls, the use of a narrower bandwidth and of alternative measures of sleep duration. As twelve of the continental US states span multiple time zones, in column 2, we re-estimate the first-stage while including a full set of state fixed effects. Notably, the point estimates remain substantially unchanged. In column 3, we restrict our attention to a very narrow bandwidth of 100 miles. As the discontinuity in sunset time is larger at the border and diminishes with the distance from the border, it is not surprising to find even a larger effect on sleep duration. The coefficient indicates that within 100 miles of the border, individuals on the eastern side sleep on average 23 fewer minutes than their neighbors on the western side. Finally, column 4 shows that there is also a large effect on the probability of sleeping less than 8 hours. Being on the eastern side of the boundary decreases the likelihood of sleeping at least 8 hours by 8.2 percentage points, which is equivalent to approximately $16 \%$ of the mean of the dependent variable in the sample. ${ }^{16}$

\subsection{Early Morning Schedules and Sleep Duration}

In Table 3 we compare employed and non-employed respondents. Consistent with our hypothesis on working schedules' constraints on sleep duration, the first two columns show that the late sunset time on the eastern side of the time zone boundary affects only the employed respondents. Columns 3-6 clarify where the difference between employed and non-employed respondents lies. In columns 3 and 4, we show that, regardless of their employment status, individuals on the eastern side of the time zone border are always more likely to go to bed later. The estimates show that being on the eastern side of the boundary significantly increases the likelihood of being awake at midnight for both the employed $(+41 \%)$ and the non-employed (+34\%). However, employed respondents are less likely to adjust their waking time accordingly. Column 5 shows no significant difference across the border in the likelihood of being awake at 7:30am for employed people. Conversely, non-employed people on the eastern side of the time zone border adjust their waking-up time in the morning. Column 6 shows that non-employed people on the eastern side are 13 percentage points less likely to be awake at 7:30am, a 32\% effect with respect to the mean of the dependent variable.

We also hypothesize that the effects should be smaller in the retail and wholesale sector, as in most cases shops and stores in the US open relatively late in the morning (e.g, 10 or $11 \mathrm{am}$ ) and largest among individuals working in schools, in the health care sector or other public offices where standard schedules are likely to begin early in the morning or among individuals working in jobs requiring international coordination and synchronization with other markets (e.g., financial services). Consistent with our conjecture, Table A.2 shows no evidence of significant effects among individuals in the wholesale and retail sector. The coefficient reported in column 2 is both small (in absolute value) and not statistically significant. However, the effect of sunset

\footnotetext{
${ }^{16}$ As mentioned above, most respondents are interviewed over the weekend, and people tend to sleep longer over the weekend, thus to better gauge the magnitude of the sleep differences, we weighted the means reported at the bottom of the table to represent an average day.
} 
is significantly larger among individuals working in the educational or health sectors or in other public offices. The coefficient reported in column 3 suggests that a one-hour increase in the timing of sunset would decrease sleeping by approximately 40 minutes for individuals working in these sectors. Column 3 shows a similar effect for individuals working in financial services.

In Table 4, we directly analyze whether the discontinuity in sleep duration is affected by individuals' early morning constraints: working schedules and school start times. Note that to conduct this analysis, we restricted the sample to individuals who reported to work on the day of the interview. As $50 \%$ of the ATUS sample is interviewed over the weekend and only $23 \%$ of the employed sample reported having worked over the weekend, the sample is substantially restricted. Column 1 shows that the first-stage is largest among individuals starting work before 7am. For these workers, a one-hour increase in average sunset time decreases sleep duration by 36 minutes. The coefficient is smaller but still negative and significant among individuals starting work between 7 and 8:30am (column 2). For this group, a one-hour increase in average sunset time would reduce sleep duration by approximately 18 minutes. By contrast, we find that there is no significant effect on individuals starting work between 8:30am and noon (column 3). ${ }^{17}$ The effect is not only not statistically significant but also very small in absolute value. However, even among those starting work after 8:30 am, individuals who left children at school before 8am sleep substantially less and there is a large and significant effect of sunset time (column 4). In particular, among those entering work later in the morning, a one-hour increase in average sunset time decreases sleep duration by 27 minutes for those who brought children to school before 8am. Consistent with these findings, Table A.3 in the Appendix, shows that the estimated effect is larger for people with children younger than 13 even when including the non-employed.

These findings suggest that delaying work and school start times may have important effects on average sleep duration. Table A.5, shows that even when we analyze the entire ATUS sample, without restricting the analysis to counties closer to the time zone boundaries, individuals with early working schedules and/or whose children have early school start times sleep significantly less than individuals who are less likely to be constrained by social schedules in the morning (see columns 2 and 3). Furthermore, the fact that the heterogeneity of the results presented in this section confirms our main hypotheses is reassuring and suggests that we are not confounding the effect of late sunset with that of other factors.

\subsection{The Role of TV Schedules}

Next, we investigate the role that the television plays in affecting bedtime and sleep duration. The assumption underlying our identification holds as long as differences in sleeping are induced by differences in exogenous natural or artificial factors. However, understanding whether TV schedules mediate the effect of sunset cues is important for understanding the mechanisms underlying our first-stage regression and what policies could affect sleeping duration. Specif-

\footnotetext{
${ }^{17}$ We classify individuals in these 3 categories to compare groups of similar size and based on the distribution of working schedules.
} 
ically, we want to determine to the extent to which the marked discontinuity we observed in bedtime and sleep duration at the three time zone borders is affected by the different timing of TV shows and prime times across US time zones. As largely explained in Section 2.2, in the two middle time zones, prime time shows typically air an hour earlier than in the Eastern and Pacific time zones. This difference in television schedules across time zones may exacerbate the effect of the different sunset times at the time zone border in areas where the later sunset is associated with a later TV schedule (e.g., counties in the Eastern time zone at the boarder with the Central time zone). Conversely, we would expect television schedules to mitigate the effect of a later sunset on sleeping in areas where the later sunset is associated with an earlier TV schedule (e.g., counties in the Mountain time zone at the boarder with the Pacific time zone).

Specifically, as prime time shows air an hour earlier in the middle time zones, we might expect, holding all else constant, the discontinuity in bedtime to be larger along the EasternCentral (EC) time zone border and lower along the Mountain-Pacific (MP) time zone border, while TV schedules should play no role at the Central-Mountain (CM) zone border. For this reason, in Table 5, we exploit the heterogeneity at the three time zone borders to investigate the role played by television. In particular, in column 1, we estimate the effect of living on the eastern side of a time zone border on sleep duration (as in column 1 of Table 2) but adding to the model in equation (2) two dummies for the CM and and MP borders that we interact with the dummy identifying individuals living on the eastern side of the time zone boundary $\left(E B_{c}\right)$. In this way, we can test whether there is evidence of heterogeneity in the effect of interest across time zone borders. The results reported in column 1 show that the effect is significantly larger at the CM border than at the other two time zone borders. This evidence contrasts with the hypothesis that TV is the main factor explaining the discontinuity in sleep duration we observed at the time zone border. As mentioned above, as TV shows are broadcast earlier in the two middle time zones, we would have expected a larger effect at the EC time zone boundary and a smaller effect along the MP border. However, it is worth noting that, in our sample, we have only 1,742 observations from the CM border. These individuals are likely to be concentrated primarily in urban and populated areas because we cannot identify counties or metropolitan areas with fewer than 100,000 residents. ${ }^{18}$

For this reason, in column 2, we also exploit the bedtime data from Jawbone presented in Figure 4. This dataset is likely not to be representative of the US population ${ }^{19}$ and does not allow us to focus solely on the employed people as in our sample, but in contrast to the ATUS, it contains information on all US counties. As we lack information on individual sleeping time and on individual socio-economic characteristics, we use county-level controls. Furthermore, we focus only on bedtime because wake-time data might be affected by the compensatory behavior of non-employed people (as already shown in column 6 of Table 3) and may be more sensitive to

\footnotetext{
${ }^{18}$ In Table, A.8, we show that the effect of interest is larger in more populated metropolitan areas, and the larger effect estimated along the CM border might be the consequence of the sample selection criterion.

${ }^{19}$ It is reasonable to expect that young people from urban areas are more likely to use personal wearables tracking sleep quality and calorie expenditure.
} 
the particular personal wearable model used to track sleep. The results using Jawbone data do not reveal evidence of substantial heterogeneity across time zone borders. In contrast to column 1, we only have evidence of a significantly smaller effect at the MP border, consistent with a, rather small, mitigating effect of TV.

\subsubsection{Sweeps Weeks and Sleep Duration}

In a further attempt to assess the importance of TV schedules and programs in determining individuals' bedtimes, we also consider differences in sleep duration induced by the attractiveness of TV shows during the year. To this end, we exploit the fact that all major TV broadcasters strive to maximize audience ratings during the Nielsen "sweeps" rating periods. Each year in the months of November, February, May and $\mathrm{July}^{20}$, Nielsen Media Research, the company that records viewing figures for television programs, sends out diaries to sample homes in the various markets around the country for the residents to record the shows they viewed. During these weeks, TV networks air new episodes, series and specials in an effort to boost their viewing figures and, hence, advertising revenue. As a consequence, during these weeks, we might expect that if TV is a major determinant of individual bedtime habits, people would tend to sleep later than in other periods of the year because of the particular appeal of TV schedules during these weeks.

Using the exact dates of sweeps weeks between 2003 and 2013, we exploit this exogenous change in broadcast programming. Specifically, we test whether the discontinuity at the time zone border is larger (or smaller) during sweeps weeks (column 4, Table 5). If television plays a role in explaining the large discontinuity in sleep duration at the time zone borders, we should observe a larger effect during these weeks when more people are likely to watch TV shows. To test this hypothesis, we interact the dummy identifying individuals living on the eastern side of a time zone boundary with a dummy that is equal to one for interviews conducted during a sweeps week. The results clearly show that there is no evidence of heterogeneity in the discontinuity at the time zone border during these sweeps weeks. However, we do find evidence that during these weeks people tend to go to bed later and sleep less (approximately 6 minutes). Ultimately, although television schedules influence bedtime and sleep duration (as noted by Hamermesh et al., 2008), our analysis suggests that television does not play a major role in explaining the discontinuity we observed at the time zone border.

\section{Effects of Sleeping on Health Status and Weight}

We exploit the discontinuity in sleep duration to evaluate the effects of sleep on overweight status, obesity and self-reported health status. Again, we focus on the employed population,

\footnotetext{
${ }^{20}$ They are 4 consecutive weeks that lie mainly in the months of November, February, May and July usually starting from the Thursday of the previous month.
} 
as we have shown that there is no significant discontinuity in sleep duration among the nonemployed. As noted above, information on health status and body mass index is not available in all ATUS survey waves; thus, we have limited identification power. Nevertheless, the results in Table 6 show a significant effect for both health outcomes. In particular, columns 1 and 2 report the reduced-form and 2SLS estimates on overweight status, columns 3 and 4 the effects on obesity, while columns 5 and 6 illustrate the effects on poor health. Employed individuals living on the eastern side of a time zone border are $10 \%$ more likely be overweight with respect to the mean (column 1). They are also 6 percentage point more likely to be obese, approximately $22 \%$ with respect to the mean of the dependent variable in the sample under analysis (column 3 ). With regard to self-reported health status, column 5 shows that the effect is equal to nearly 3 percentage points, almost $30 \%$ of the sample mean. Given the binary nature of our outcome variables we also replicate our analysis using the probit model. The marginal effects are substantially identical and available upon request.

The IV estimates (columns 2, 4, and 6) are obviously larger because of the fuzzy design of our RD strategy. As noted above, these estimates must be interpreted with caution. These health differences, especially in the case of obesity, are likely to be the result of long-term exposure to sleep differences (caused by the different sunset time) on the two sides of a time zone border. Decreasing sleep duration by 19 minutes $^{21}$, the average difference in sleep duration observed at a time-zone border in the whole sample, increases overweight status by $7 \%$, obesity by $16 \%$, and the likelihood of reporting poor health status by $26 \%$ with respect to the mean. As mentioned above, these effects are large but in terms of magnitude they are comparable with the evidence available from animal studies (Knutson et al., 2007) and with the associations found in observational studies (Moreno et al., 2006; Hasler et al., 2004; Cappuccio et al., 2008).

Table 7 illustrates the heterogeneity of our results with respect to age groups. Consistent with our conjecture, columns 1-4 show that the reduced-form effect on overweight status and obesity is concentrated among older workers (columns 2 and 4), who have been exposed to the treatment for longer than have younger workers (column 1 and 3). Conversely, the age gradient is small and not statistically significant when examining health status (columns 5 and 6). These differences are not surprising because self-reported health status is more likely to capture the short-term effects of sleep deprivation on health perception. In other words, self-reported health status is more likely to reflect the effects of short-term variations in sleep duration, while obesity is more likely to reflect the cumulative effect of sleep deprivation over time. These findings are also consistent with the findings of Spiegel et al. (1999) who show that chronic sleep debt has a harmful impact on carbohydrate metabolism and endocrine function.

\footnotetext{
${ }^{21}$ Note that the first-stage is larger in the sample for which we have information on BMI and health status, indicating an average difference in sleep duration at the border of 27 and 23 minutes, respectively. However, the standard errors are relatively large, and thus, the first-stage result is not statistically different from that reported in Table 2 indicating that individuals on the the eastern side of a time zone border sleep approximately 19 minutes less than their neighbors living in counties on the opposite side.
} 


\subsection{Cognitive Impairment: Analysis Based on the 2000 US Census}

Evidence from the medical literature suggests that sleep loss is associated with lower brain activity and significantly affects mental alertness and our cognitive processes. Using data from the 2000 US Census, we investigate the presence of a discontinuity in cognitive impairment across the time zone border. In particular, the 2000 US Census contains information on whether the respondent has cognitive difficulties (such as learning, remembering, concentrating, or making decisions) because of a physical, mental, or emotional condition.

Table 8 shows that individuals living on the eastern side of the time zone boundary are more likely to report cognitive problems. In column 1, we find that being on the late sunset side of the border increases the likelihood of reporting cognitive problems by 0.004 percentage points, a $25 \%$ effect with respect to the mean of the dependent variable in the sample (0.016). The point estimate is larger when restricting the bandwidth to 100 miles (column 2) while the coefficient remains positive and significant when including state fixed effects (column 4). Since census data do not contain information on sleeping behavior, in column 4-6 we estimate the effect of sleep duration on cognitive impairment using a two-sample two-stage least squares (TS2SLS). In particular, we match the individuals in the two samples (ATUS and 2000 US Census) using their geographical location and standard socio-democratic information (sex, age, race, education and marital status). As for obesity and poor health, IV estimates are particularly large as they capture the effects of a long-term exposure to sleep deprivation. Interestingly, these results are consistent with what observed in a companion study analyzing the effects of sleep deprivation on cognitive skills in China using more standard measure of cognitive skills (Giuntella et al., 2015).

\subsection{Potential Mechanisms}

The medical literature offers clear biological explanations for the effects of sleep deprivation on weight gain. As mentioned above, medical research has shown that insufficient sleep affects the function regulating appetite and energy expenditure. Previous studies offer evidence that food intake is a physiological adaptation to provide energy needed to sustain additional wakefulness and that sleep duration plays a key role in energy metabolism (Markwald et al., 2013), favoring the consumption of fats and carbohydrates. Furthermore, fatigue due to sleep loss may reduce physical activity, exacerbating the effects of sleep deprivation on weight gain. In this section, we examine how individuals' time use and activities may respond to these biological mechanisms and affect caloric intake and expenditure.

\section{Eating Habits}

Insufficient sleep may increase calorie intake, particularly in the evening as individuals begin to feel tired and the need for energy to keep themselves awake. Markwald et al. (2013) present evidence of how changes in circadian rhythms may contribute to altered eating patterns given insufficient sleep. In particular, they argue that a delay in melatonin onset, altering the beginning 
of biological night, may lead to a circadian drive for more food intake at night. To verify whether this channel may contribute to explaining our findings, we examine individuals' eating patterns on the two sides of the time zone border.

Table 9 documents that individuals on the eastern side of a time zone border are more likely than their neighbors on the opposite side of the border to eat after a given hour. In particular, the former are $30 \%$ more likely to begin a meal after $6 \mathrm{pm}, 46 \%$ more likely to begin a meal after $7 \mathrm{pm}$, and $50 \%$ more likely to begin a meal after $8 \mathrm{pm}$. These results hold when accounting for the number of meals one has had before $6 \mathrm{pm}, 7 \mathrm{pm}$, and $8 \mathrm{pm}$, respectively, suggesting that people are not merely shifting eating time to a later hour but are more likely to eat after a given hour regardless of the number of times they had eaten or the time they had spent eating earlier in the day.

Another possible explanation for the effects of sleep deprivation on weight gain is that if individuals sleeping less are more tired in the evening, they may also be less willing to eat in and more willing to eat out. Indeed, previous studies show that because restaurants routinely serve food with more calories than needed, dining out represents a risk factor for overweight and obesity (Cohen and Story, 2014). To test this hypothesis, in Table 10, we use information on the location of each activity reported in the ATUS time diary and construct indicators for whether individuals consumed their meal at home or out.

Column 1 shows that individuals on the eastern side of the time zone boundary are 4 percentage points more likely to eat out. The coefficient remains stable once we control for the overall number of meals (column 2). However, the estimates are imprecise. Note also that columns 1 and 2 include lunches at the workplace. In columns 3 and 4, we focus on the likelihood of having dinner out, measured as dining out after $5 \mathrm{pm}$. Individuals on the eastern side of the time zone border are 8 percentage points more likely to eat out after $5 \mathrm{pm}$. Conversely, we find no significant differences among non-employed individuals at the borders for both the likelihood of having late meals after a certain hour and the likelihood of dining out (results are available upon request). Again, the results hold if we control for the number of meals one had before $5 \mathrm{pm}$ or the overall time spent eating. Together, these findings suggest that insufficient sleep may affect weight gain through its effects on the likelihood of having more meals/snacks after a given hour and the likelihood of dining out. The these results are robust to the inclusion of controls for the

previous number of meals/average time spent on previous meals suggests that these differences in eating behaviors may lead to a net increase in caloric intake.

\section{Physical Activity}

Another potential explanation for the effect of sleeping on weight is that insufficient sleep may reduce calorie expenditure because tired individuals are less likely to engage in physical activities. Using ATUS data on time spent walking, biking, or doing any type of sporting activity, we do not find any evidence of significant differences between individuals on opposite sides of time zone borders. However, we find some evidence that individuals on the eastern side of the 
time zone border are less likely to engage in activities of moderate, vigorous, or very vigorous intensity using metabolic equivalents associated with each activity reported in the ATUS time diary. ${ }^{22}$ Following Tudor-Locke et al. (2009), who use information from the Compendium of Physical Activities to code physical activities derived from the ATUS, we classify the reported activities based on their intensity (see also Haskell et al. (2007)). ${ }^{23}$ Specifically, we classify activities into sleeping $(M E T<0.9)$, sitting $(M E T \in[0.9 ; 1.5])$, light activities $(M E T \in[1.5 ; 3])$, moderate activities $(M E T \in[3 ; 6])$, vigorous activities $(M E T \in[6 ; 9])$, and very vigorous activities $(M E T>9)$. Using this classification, in Table 11, we test whether individuals on the eastern side of the time zone boundary are more or less likely to engage in moderate or vigorous activities for more than 30 minutes. ${ }^{24}$ We find that they spend less time performing moderate or vigorous physical activity. The coefficient reported in column 1 indicates that in counties on the eastern side of the time zone boundary, individuals are two percentage points less likely to conduct moderate or vigorous physical activity for longer than 30 minutes. The coefficient reported in column 1 is only marginally significant. However the point estimate becomes larger and more precisely estimated when, as in Table A.3, we focus on individuals with children under the age of 13 in the household (column 2), while the estimate is not significantly different from zero for individuals without children under the age of 13 (see column 3).

As noted by Tudor-Locke et al. (2009), the use of the ATUS dataset for the study of physical activity has a number of limitations, as only one activity at a time is captured, and hence any physical activity secondary to a primary activity would not be counted. Furthermore, the ATUS is based on the time diaries of randomly selected adults in the United States for a single 24hour period, and thus, the data may not characterize habitual physical activity behaviors of individuals or selected population groups. For this reason, we present further analysis using county-level data on physical activity made available by the Institute for Health Metrics and Evaluation (IHME) (see Table 12). IHME provides data on physical activity as calculated by Dwyer-Lindgren et al. (2013), who use data from the Behavioral Risk Factor Surveillance System (BRFSS) to generate estimates of physical activity prevalence for each county annually for 2001 to 2011, using small area estimation methods (Srebotnjak et al., 2010). ${ }^{25}$

We used 2011 data for both men and women. Column 1 shows that individuals living on the eastern side of the time zone border are 1 percentage point less likely to report sufficient physical activity. Note that these are county-level estimates based on the entire population. Therefore, the

\footnotetext{
${ }^{22}$ Metabolic equivalents are a physiological measure expressing the energy cost of physical activities and defined as the ratio of metabolic rate (and therefore the rate of energy consumption) during a specific physical activity to a reference metabolic rate.

${ }^{23}$ The Compendium of Physical Activities is used to code physical activities derived from various sources to facilitate their comparability.

${ }^{24}$ The 2008 Physical Activity Guidelines for Americans guidelines indicate that adults should engage in 150 minutes of moderate-intensity aerobic activity, 75 minutes of vigorous activity or an equivalent combination of moderate and vigorous aerobic activity each week. Adults should engage in muscle-strengthening activities at least 2 days per week. See http://www.health.gov/paguidelines.

${ }^{25}$ The data can be downloaded at http://www.healthdata.org/us-county-profiles. IHME's US county performance research compiles available national and local health data from throughout the United States.
} 
estimated effect would be even larger if we could focus on employed individuals aged 18-55 as in our main analysis. Consistent with this conjecture, column 2 shows that in high-unemployment areas (above the median) the effect is close to zero while column 3 indicates that the effects are larger in absolute value in counties with a lower share of over-65 persons (below the median). Again, the heterogeneity across areas suggests that these results are driven by the employed population and that part of the effect on weight may be explained by differences in physical activity.

The evidence obtained using ATUS and IHME data is consistent with recent evidence from lab studies showing that sleep deprivation significantly reduces physical activity and, thus, caloric expenditure (Schmid et al., 2009; Opstad and Aakvaag, 1982).

\section{Robustness Checks}

In this section, we present additional tests that we implement to verify the validity of our identification strategy and the robustness of our results.

First, we test the unconfoundedness hypothesis underlying our RD design. Following standard practice in RD designs, we verify whether there are discontinuities in predetermined characteristics known not to be affected by the treatment (sleeping). In the presence of other discontinuities, the estimated effect may be erroneously attributed to the treatment of interest.

As discussed in Section 3.1, a natural concern is that residential sorting across the time zone border will create correlation between unobservable individual characteristics and individual residence. As we control for latitude and, thus, hold daylight duration fixed, sorting would bias our estimates only if individuals sort based on the timing of daylight. We conduct a variety of tests for residential sorting and find no evidence for it. Specifically, we test whether there are differences in body height using the same estimation strategy used to test the presence of discontinuities in sleeping. The results in the first column in Table A.6 do not show any difference in height on the two sides of the time zone border. This result is consistent with the evidence from the balancing test presented in Table 1.

Furthermore, we verify whether there were historical differences between the two sides of the time zones before the adoption of the time zones in the US in 1914. In particular, we use the 1900 US census to test whether there was a discontinuity in literacy rates across the current time zone borders. Column 2 of Table A.6 shows the result of this test. As above, this test does not cast doubt on our identification strategy.

In Table A.7, we test for the presence of discontinuities in home and rent prices, population density and commuting time. We find no evidence of residential sorting on these important local characteristics that should be affected if people systematically preferred to locate on a given side of the time zone border.

While we cannot identify counties or metropolitan areas with fewer than 100,000 residents, in Table A.8 we illustrate the heterogeneity in the first-stage estimates by the size of the metropoli- 
tan area of residence. The results suggest that the effect is larger in more populated metropolitan areas, likely reflecting differences in the occupational and demographic characteristics of individuals living in smaller cities but also the longer commuting that many people may face in the morning in large metropolitan areas.

Table A.1 re-estimates the first-stage discussed in Table 2 using alternative metrics for sleep duration. Column 1 replicates the result presented in column 1 of Table 2 that excluded naps from the count, defined as any sleep duration occurring between 7am and 7pm and lasting less than 2 hours. In column 2, we show that the coefficient is substantially unchanged if we include naps. We then focus on non-linear metrics of sleep duration that have been used in medical studies (Ohayon et al., 2013; Markwald et al., 2013). In particular, we examine the likelihood of sleeping less than 6 hours (insufficient sleep, column 3), at least 8 hours (sufficient sleep, column 4), and at least 8 hours but no more than 9 (sufficient but not excessive sleep, column $5)$. Individuals on the eastern side of the time zone border are 4 percentage points more likely to report less than 6 hours sleep (column 3), 8 percentage points less likely to report at least 8 hours' sleep (column 4), and 3 percentage points less likely to report sufficient but not excessive sleep (column 5). However, we find no differences in naps measured as the total amount of time slept between $11 \mathrm{am}$ and $8 \mathrm{pm}$ (see column 6).

In Table A.4 we investigate the heterogeneity of the reduced form effects by morning work schedules. Point estimates for overweight and obesity are proportional to the first stage results. In particular, as for the first-stage estimates analyzed in Table 4, point estimates are (at least) twice the average effect in column (1), very similar to the average effect in column 2 and closer to zero (or even negative) in column (3). Unfortunately, standard errors are very large because the sample size for this analysis is very small. Despite this, the point estimates for early schedule workers are still statistically different from zero. It is worth noting these results could be also explained by the presence of non-linearity because those with very early schedule sleep much less on average. Unfortunately, with such data we cannot disentangle the presence of nonlinearity from a "compliance" explanation-where the estimated effect is driven by those that are constrained and then more likely to be exposed to the negative effects of a late sunset.

Furthermore, we verify the robustness of our results by excluding one US state at a time from our estimates. This exercise is meant to determine whether our results are driven by the presence of one particular state. The results, available upon request, confirm the robustness of our findings.

We also investigate the presence of seasonal and geographical heterogeneity in the discontinuity at the time zone borders and whether this heterogeneity is related to the daylight duration. For instance, in the North daylight duration varies far more across seasons than in the South. Even tough point estimates might suggest the presence of some heterogeneity (i.e. larger seasonal heterogeneity in the North than in the South), differences across seasons and latitudes (North vs. South) are almost never statically significant (results are available upon request).

Finally, we tested for the optimal polynomial order by comparing our local linear regres- 
sion approach with higher polynomial orders (up to the fourth) using the well-known Akaike information criterion (AIC) and the Bayesian information criterion (BIC). Both the AIC and BIC are minimized using the local linear regression approach reported in our main text (results are available upon request).

\section{Conclusion}

This paper investigated the causal effects of sleeping on health status and excessive weight, two outcomes that are known to be importantly related to health care costs and individual productivity. We exploit discontinuities in bedtime that occur at a time zone boundary because of solar cues, circadian rhythms and their conflict with social schedules. We show that individuals living on the eastern side of a time zone boundary tend to go to bed later than do individuals living in the neighboring counties on the opposite side of the time zone border. Because working schedules and school start times are less flexible than bedtimes, individuals on the eastern side of the border do not fully compensate by waking up later in the morning. Thus, we find that employed individuals living on the eastern side of a time zone border sleep less than people living in a neighboring county on the western side of a time zone boundary. Though the average difference in sleep duration is relatively small (19 minutes), the effects are considerably larger among individuals with early working schedules.

Using this exogenous variation in sleep duration, we find large effects of sleeping on individuals' health status, weight and cognitive impairment. These results support and extend the experimental evidence on the cumulative effects of partial sleep deprivation, a condition that increasingly affects the life of individuals in modern societies. Our findings suggest that the higher propensity to eat late in the evening, regardless of the time spent eating earlier in the day, the higher likelihood of dining out and lower likelihood of engaging in moderate or intense physical activity contribute to explaining the effects on weight and health status. The results are robust to the use of different models and measures of sleep duration. Importantly, we find no evidence of any significant effect on outcomes that should not be affected by sleep duration.

Economists have largely ignored the effects of sleep on health and how economic incentives or changes in policies (e.g., changes in DST dates) can affect sleeping and have unintended consequences on health and productivity. Our findings highlight the importance of developing public awareness about the negative effect of sleep deprivation and suggest that policy makers should carefully consider how working schedules and time zone rules can affect sleep duration and quality. In fact, our results suggest that delaying morning work schedules and school start times may substantially improve average sleep duration. While we are unable to compare the economic gains that may result from coordination with its costs in terms of health and human capital, our results highlight that the latter are not negligible. As long work hours, work schedules, school start times and the timing of TV shows can create conflicts between our biological rhythms and social timing, our findings suggest that reshaping social schedules in ways that promote sleeping 
may have non-trivial effects on health. In particular, we find that delaying work start times until after 8:30am would substantially increase average sleep duration.

Finally, considerable attention has been devoted in recent years to the obesity epidemic (Cawley, 2015), particularly in the United States, with the implementation of several state and federal programs intended to reduce obesity. Most of these programs promote healthy nutrition and physical activity. Our results suggest the importance of increasing the spectrum of these public health interventions by including policies intended to increase average sleep duration and a healthier use of our time. Sleep education programs should become a central part of any program seeking to reduce obesity and weight gain among at-risk populations. 


\section{References}

Altevogt, B. M., Colten, H. R., et al., 2006. Sleep Disorders and Sleep Deprivation:: An Unmet Public Health Problem. National Academies Press.

Aschoff, J., Fatranska, M., Giedke, H., Doerr, P., Stamm, D., Wisser, H., 1971. Human circadian rhythms in continuous darkness: entrainment by social cues. Science 171 (3967), 213-215.

Ásgeirsdóttir, T. L., Ólafsson, S. P., 2015. An empirical analysis of the demand for sleep: Evidence from the american time use survey. Economics \& Human Biology.

Barger, L. K., Cade, B. E., Ayas, N. T., Cronin, J. W., Rosner, B., Speizer, F. E., Czeisler, C. A., 2005. Extended work shifts and the risk of motor vehicle crashes among interns. New England Journal of Medicine 352 (2), 125-134.

Basner, M., Fomberstein, K. M., Razavi, F. M., Banks, S., William, J. H., Rosa, R. R., Dinges, D. F., 2007. American time use survey: sleep time and its relationship to waking activities. Sleep 30 (9), 1085.

Bergstrom, T., 1976. The deeper economics of sleeping. The Journal of Political Economy, 411-412.

Biddle, J. E., Hamermesh, D. S., 1990. Sleep and the allocation of time. Journal of Political Economy 98, 922-943.

Bonke, J., 2012. Do morning-type people earn more than evening-type people? How chronotypes influence income. Annals of Economics and Statistics/ANNALES D'ÉCONOMIE ET DE STATISTIQUE, 55-72.

Brochu, P., Armstrong, C. D., Morin, L.-P., 2012. The trendiness of sleep: an empirical investigation into the cyclical nature of sleep time. Empirical Economics 43 (2), 891-913.

Burton, W. N., Chen, C.-Y., Conti, D. J., Schultz, A. B., Pransky, G., Edington, D. W., 2005. The association of health risks with on-the-job productivity. Journal of Occupational and Environmental Medicine 47 (8), 769-777.

Cappuccio, F. P., D’Elia, L., Strazzullo, P., Miller, M. A., 2010. Sleep duration and all-cause mortality: a systematic review and meta-analysis of prospective studies. Sleep 33 (5), 585.

Cappuccio, F. P., Taggart, F. M., Kandala, N., Currie, A., Peile, E., Stranges, S., Miller, M. A., 2008. Meta-analysis of short sleep duration and obesity in children and adults. SLEEP-NEW YORK THEN WESTCHESTER- 31 (5), 619.

Carrell, S. E., Maghakian, T., West, J. E., 2011. A's from zzzz's? The causal effect of school start time on the academic achievement of adolescents. American Economic Journal: Economic Policy 3 (3), 62-81. 
Cawley, J., 2004. The impact of obesity on wages. Journal of Human Resources 39 (2), 451-474.

Cawley, J., 2015. An economy of scales: A selective review of obesity's economic causes, consequences, and solutions. Journal of health economics 43, 244-268.

Cohen, D. A., Story, M., 2014. Mitigating the health risks of dining out: the need for standardized portion sizes in restaurants. American journal of public health 104 (4), 586-590.

Dinges, D. F., Pack, F., Williams, K., Gillen, K. A., Powell, J. W., Ott, G. E., Aptowicz, C., Pack, A. I., 1997. Cumulative sleepiness, mood disturbance and psychomotor vigilance performance decrements during aweek of sleep restricted to 4-5 hours per night. Sleep: Journal of Sleep Research \& Sleep Medicine.

Duffy, J. F., Wright, K. P., 2005. Entrainment of the human circadian system by light. Journal of Biological Rhythms 20 (4), 326-338.

Dwyer-Lindgren, L., Freedman, G., Engell, R. E., Fleming, T. D., Lim, S. S., Murray, C., Mokdad, A. H., 2013. Prevalence of physical activity and obesity in us counties, 2001-2011: a road map for action. Popul Health Metr 11 (1), 7.

Edwards, F., 2012. Early to rise? The effect of daily start times on academic performance. Economics of Education Review 31 (6), 970-983.

El Hodiri, M., 1973. The economics of sleeping. Unpublished manuscript, University of Kansas.

Gibson, M., Shrader, J., 2014. Time use and productivity: The wage returns to sleep.

Giuntella, O., Han, W., Mazzonna, F., 2015. Circardian rhythms, sleep deprivation and cognitive skills. evidence from an unsleeping giant. University of Oxford, Mimeo.

Greer, S. M., Goldstein, A. N., Walker, M. P., 2013. The impact of sleep deprivation on food desire in the human brain. Nature communications 4.

Hamermesh, D. S., Myers, C. K., Pocock, M. L., 2008. Cues for timing and coordination: latitude, letterman, and longitude. Journal of Labor Economics 26 (2), 223-246.

Haskell, W. L., Lee, I.-M., Pate, R. R., Powell, K. E., Blair, S. N., Franklin, B. A., Macera, C. A., Heath, G. W., Thompson, P. D., Bauman, A., 2007. Physical activity and public health: updated recommendation for adults from the american college of sports medicine and the american heart association. Circulation 116 (9), 1081.

Hasler, G., Buysse, D. J., Klaghofer, R., Gamma, A., Ajdacic, V., Eich, D., Rössler, W., Angst, J., 2004. The association between short sleep duration and obesity in young adults: a 13-year prospective study. Sleep 27 (4), 661-666.

Hoffman, E. P., 1977. The deeper economics of sleeping: important clues toward the discovery of activity x. The Journal of Political Economy, 647-649. 
Irwin, M. R., Wang, M., Campomayor, C. O., Collado-Hidalgo, A., Cole, S., 2006. Sleep deprivation and activation of morning levels of cellular and genomic markers of inflammation. Archives of internal medicine 166 (16), 1756-1762.

Jin, L., Ziebarth, N. R., 2015. Does daylight saving time really make us sick? Tech. rep., Institute for the Study of Labor (IZA).

Kjærgaard, M., Waterloo, K., Wang, C. E., Almås, B., Figenschau, Y., Hutchinson, M. S., Svartberg, J., Jorde, R., 2012. Effect of vitamin d supplement on depression scores in people with low levels of serum 25-hydroxyvitamin d: nested case-control study and randomised clinical trial. The British Journal of Psychiatry 201 (5), 360-368.

Knutson, K. L., Ryden, A. M., Mander, B. A., Van Cauter, E., 2006. Role of sleep duration and quality in the risk and severity of type 2 diabetes mellitus. Archives of internal medicine 166 (16), 1768-1774.

Knutson, K. L., Spiegel, K., Penev, P., Van Cauter, E., 2007. The metabolic consequences of sleep deprivation. Sleep medicine reviews 11 (3), 163-178.

Knutson, K. L., Van Cauter, E., 2008. Associations between sleep loss and increased risk of obesity and diabetes. Annals of the New York Academy of Sciences 1129 (1), 287-304.

Lauderdale, D. S., Knutson, K. L., Yan, L. L., Liu, K., Rathouz, P. J., 2008. Sleep duration: how well do self-reports reflect objective measures? The cardia sleep study. Epidemiology (Cambridge, Mass.) 19 (6), 838.

Lyznicki, J. M., Doege, T. C., Davis, R. M., Williams, M. A., et al., 1998. Sleepiness, driving, and motor vehicle crashes. Jama 279 (23), 1908-1913.

Markwald, R. R., Melanson, E. L., Smith, M. R., Higgins, J., Perreault, L., Eckel, R. H., Wright, K. P., 2013. Impact of insufficient sleep on total daily energy expenditure, food intake, and weight gain. Proceedings of the National Academy of Sciences 110 (14), 5695-5700.

Moreno, C., Louzada, F., Teixeira, L., Borges, F., Lorenzi-Filho, G., 2006. Short sleep is associated with obesity among truck drivers. Chronobiology international 23 (6), 1295-1303.

Ohayon, M. M., Reynolds, C. F., Dauvilliers, Y., 2013. Excessive sleep duration and quality of life. Annals of neurology 73 (6), 785-794.

Opstad, P. K., Aakvaag, A., 1982. Decreased serum levels of oestradiol, testosterone and prolactin during prolonged physical strain and sleep deprivation, and the influence of a high calory diet. European journal of applied physiology and occupational physiology 49 (3), 343-348.

Roenneberg, T., 2013. Chronobiology: the human sleep project. Nature 498 (7455), 427-428. 
Roenneberg, T., Allebrandt, K. V., Merrow, M., Vetter, C., 2012. Social jetlag and obesity. Current Biology 22 (10), 939-943.

Roenneberg, T., Kuehnle, T., Juda, M., Kantermann, T., Allebrandt, K., Gordijn, M., Merrow, M., 2007. Epidemiology of the human circadian clock. Sleep medicine reviews 11 (6), 429-438.

Roenneberg, T., Merrow, M., 2007. Entrainment of the human circadian clock. In: Cold Spring Harbor symposia on quantitative biology. Vol. 72. Cold Spring Harbor Laboratory Press, pp. 293-299.

Schmid, S. M., Hallschmid, M., Jauch-Chara, K., Wilms, B., Benedict, C., Lehnert, H., Born, J., Schultes, B., 2009. Short-term sleep loss decreases physical activity under free-living conditions but does not increase food intake under time-deprived laboratory conditions in healthy men. The American journal of clinical nutrition 90 (6), 1476-1482.

Smith, A. C., forthcoming. Spring forward at your own risk: Daylight saving time and fatal vehicle crashes. American Economic Journal: Applied Economics.

Spiegel, K., Leproult, R., Van Cauter, E., 1999. Impact of sleep debt on metabolic and endocrine function. The Lancet 354 (9188), 1435-1439.

Srebotnjak, T., Mokdad, A. H., Murray, C., 2010. A novel framework for validating and applying standardized small area measurement strategies. Popul Health Metr 8, 26.

Stewart, J., 2014. Early to bed and earlier to rise: school, maternal employment, and childrens sleep. Review of Economics of the Household 12 (1), 29-50.

Szalontai, G., 2006. The demand for sleep: a south african study. Economic Modelling 23 (5), 854-874.

Taheri, S., Lin, L., Austin, D., Young, T., Mignot, E., 2004. Short sleep duration is associated with reduced leptin, elevated ghrelin, and increased body mass index. PLoS medicine 1 (3), e62.

Thomas, M., Sing, H., Belenky, G., Holcomb, H., Mayberg, H., Dannals, R., Wagner, J., Thorne, D., Popp, K., Rowland, L., et al., 2000. Neural basis of alertness and cognitive performance impairments during sleepiness. i. effects of $24 \mathrm{~h}$ of sleep deprivation on waking human regional brain activity. Journal of sleep research 9 (4), 335-352.

Tudor-Locke, C., Washington, T. L., Ainsworth, B. E., Troiano, R. P., 2009. Linking the american time use survey (atus) and the compendium of physical activities: methods and rationale. Journal of Physical Activity and Health 6 (3), 347-353.

Ulukavak, C. T., Kokturk, O., Bukan, N., Bilgihan, A., 2004. Leptin and ghrelin levels in patients with obstructive sleep apnea syndrome. Respiration; international review of thoracic diseases 72 (4), 395-401. 
Van Dongen, H., Rogers, N. L., Dinges, D. F., 2003a. Sleep debt: theoretical and empirical issues*. Sleep and Biological Rhythms 1 (1), 5-13.

Van Dongen, H. P., Maislin, G., Mullington, J. M., Dinges, D. F., 2003b. The cumulative cost of additional wakefulness: dose-response effects on neurobehavioral functions and sleep physiology from chronic sleep restriction and total sleep deprivation. SLEEP-NEW YORK THEN WESTCHESTER- 26 (2), 117-129.

Vitaterna, M. H., Takahashi, J. S., Turek, F. W., 2001. Overview of circadian rhythms. Alcohol Research and Health 25 (2), 85-93.

Weinger, M. B., Ancoli-Israel, S., 2002. Sleep deprivation and clinical performance. Jama 287 (8), 955-957.

Williamson, A. M., Feyer, A.-M., 2000. Moderate sleep deprivation produces impairments in cognitive and motor performance equivalent to legally prescribed levels of alcohol intoxication. Occupational and environmental medicine 57 (10), 649-655.

Winston, G. C., et al., 2008. The timing of economic activities. Cambridge Books.

Wolff, H., Makino, M., 2012. Extending becker's time allocation theory to model continuous time blocks: Evidence from daylight saving time. 
Figure 1: US sleeping over time

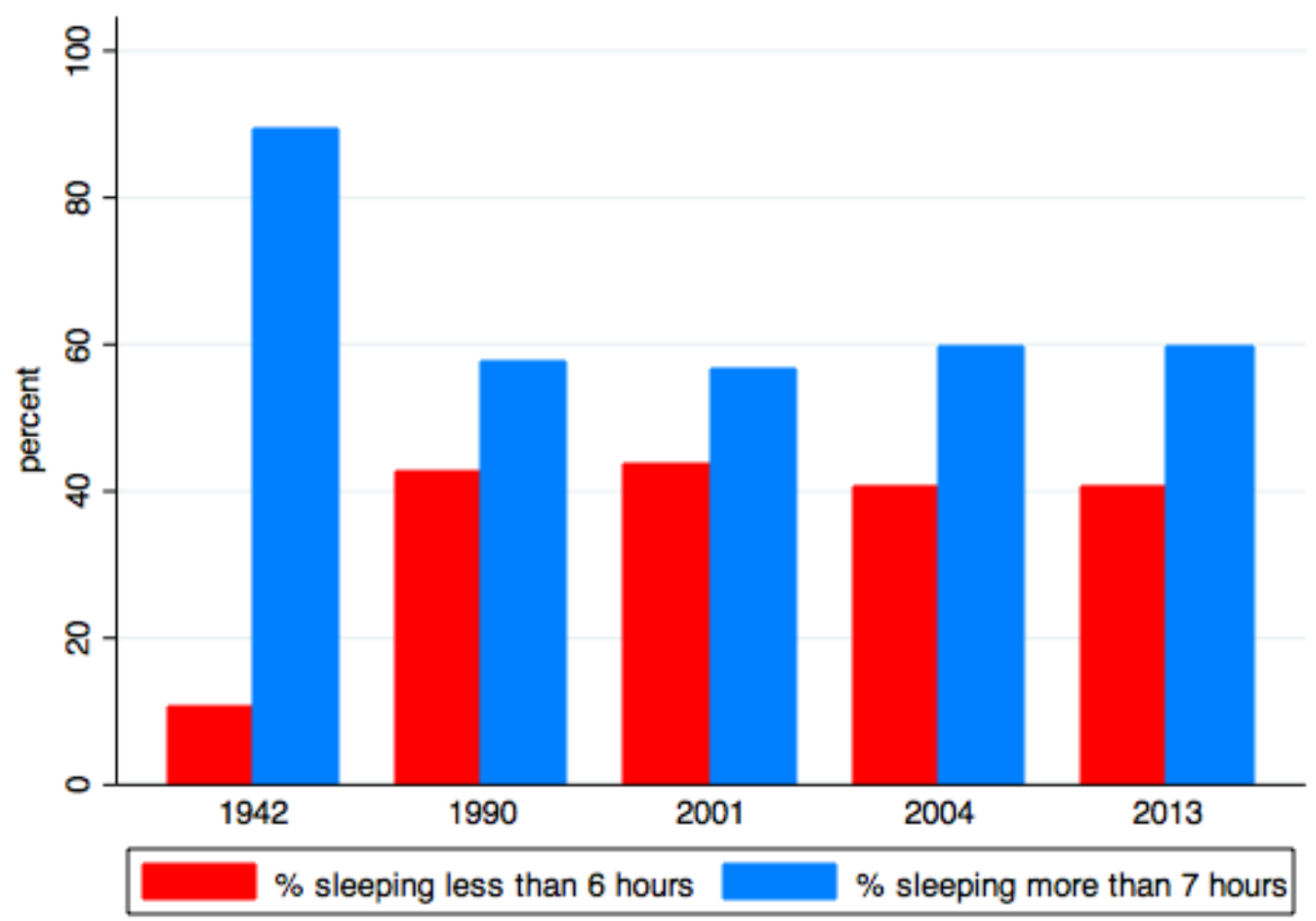

Notes - Source: Gallup, 1942-2013 
Figure 2: Sleep Deprivation by Education and Morning Work Schedule

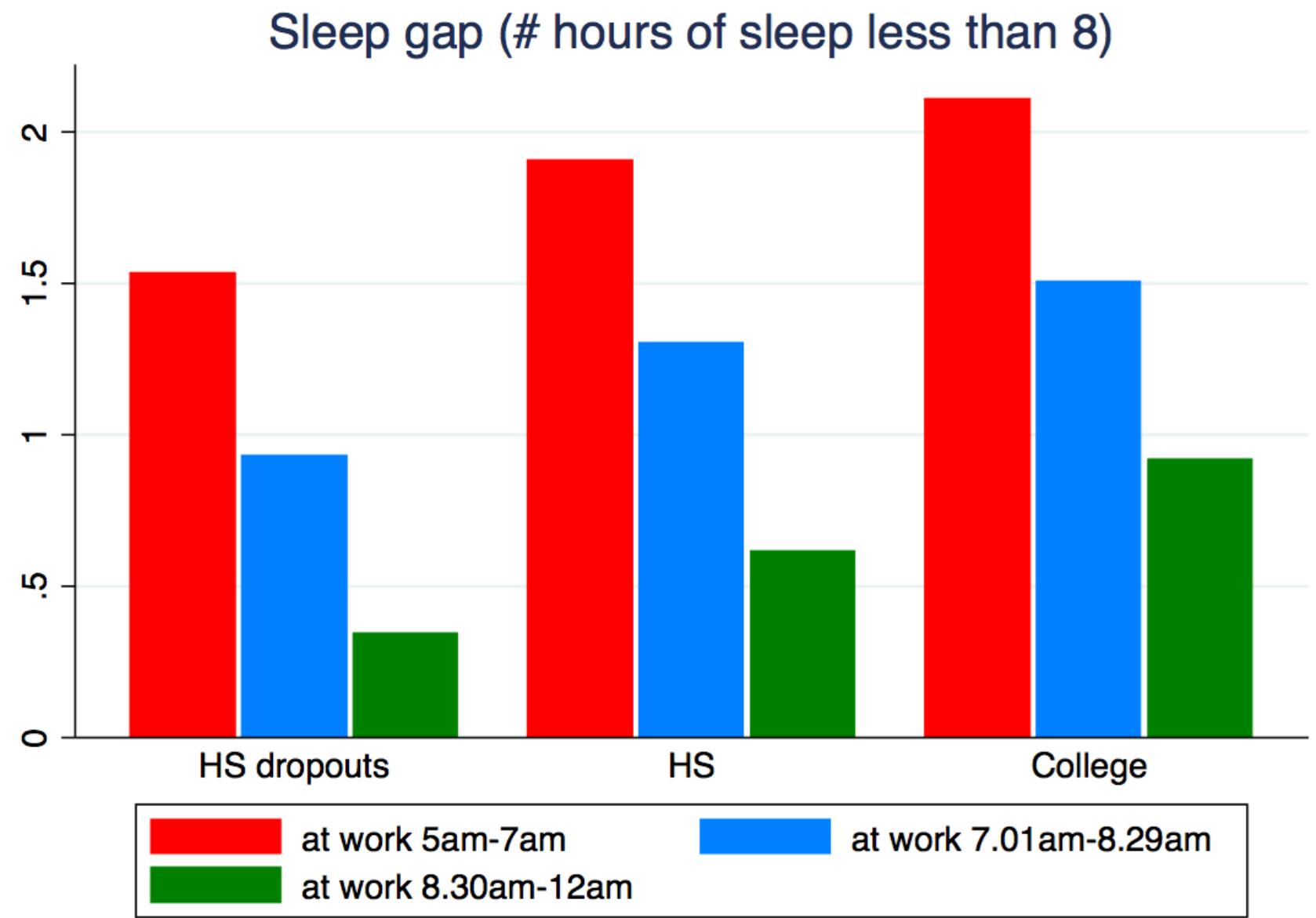

Notes - To better visualize differences in sleep duration, we report the difference between the recommended 8 hours of sleep and the observed sleep duration by education and working schedule for the average white man, aged between 40 and 50 years old, living on the East Coast. 
Figure 3: Time Zones and Average Sunset Time

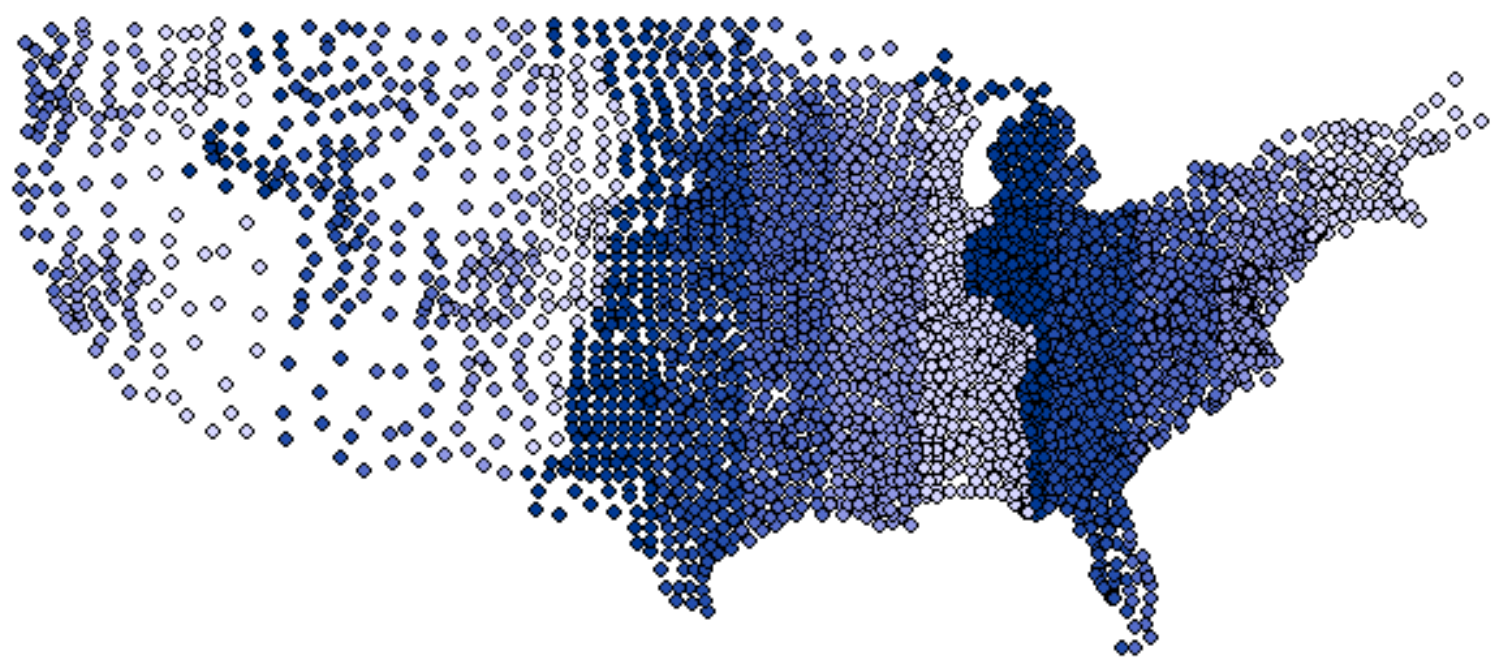

Legend

Average sunset Time

- $16.90-18.04$

- $\quad 18.04-18.27$

- $\quad 18.27-18.49$

- $18.49-18.71$

- $18.71-20.20$

Notes - Average sunset time over a year was computed using the NOAA Sunrise/Sunset and Solar Position Calculators and information on the latitude and longitude of US counties' centroids. Counties were divided into 5 quintiles based on the average sunset time in a given year. The darker the circles, the later the average sunset time. 
Figure 4: Time Zones and Bedtime (Source: jawbone.com/blog)
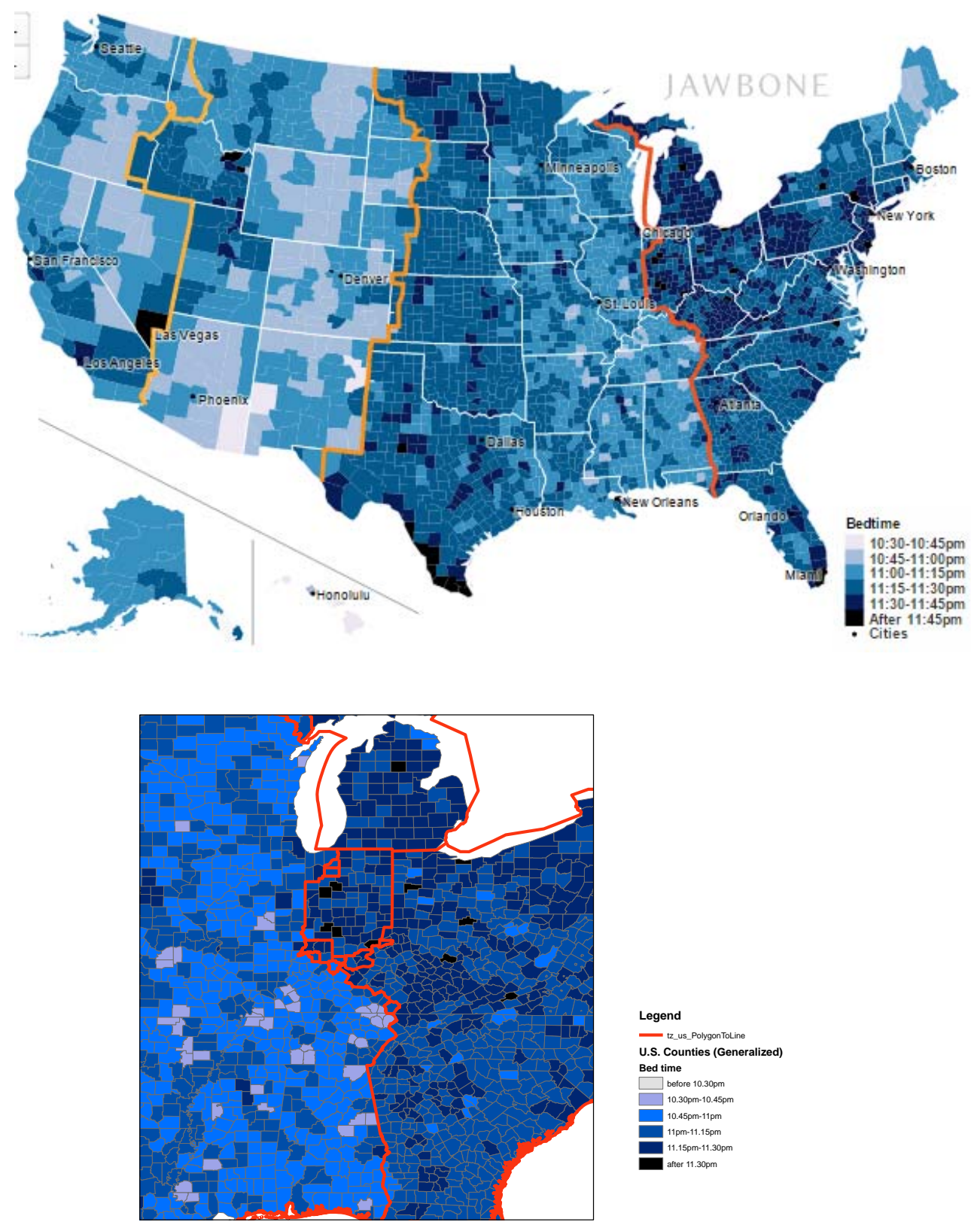

Legend

U.s. Counties (Generalized)

Bed time
$\square$ before 10.30pm

$10.30 \mathrm{pm}-10.45 \mathrm{pm}$
before

$10.45 \mathrm{pm}-11 \mathrm{pm}$

-11.15pm.11.30pm 
Figure 5: Discontinuity in Sunset Time

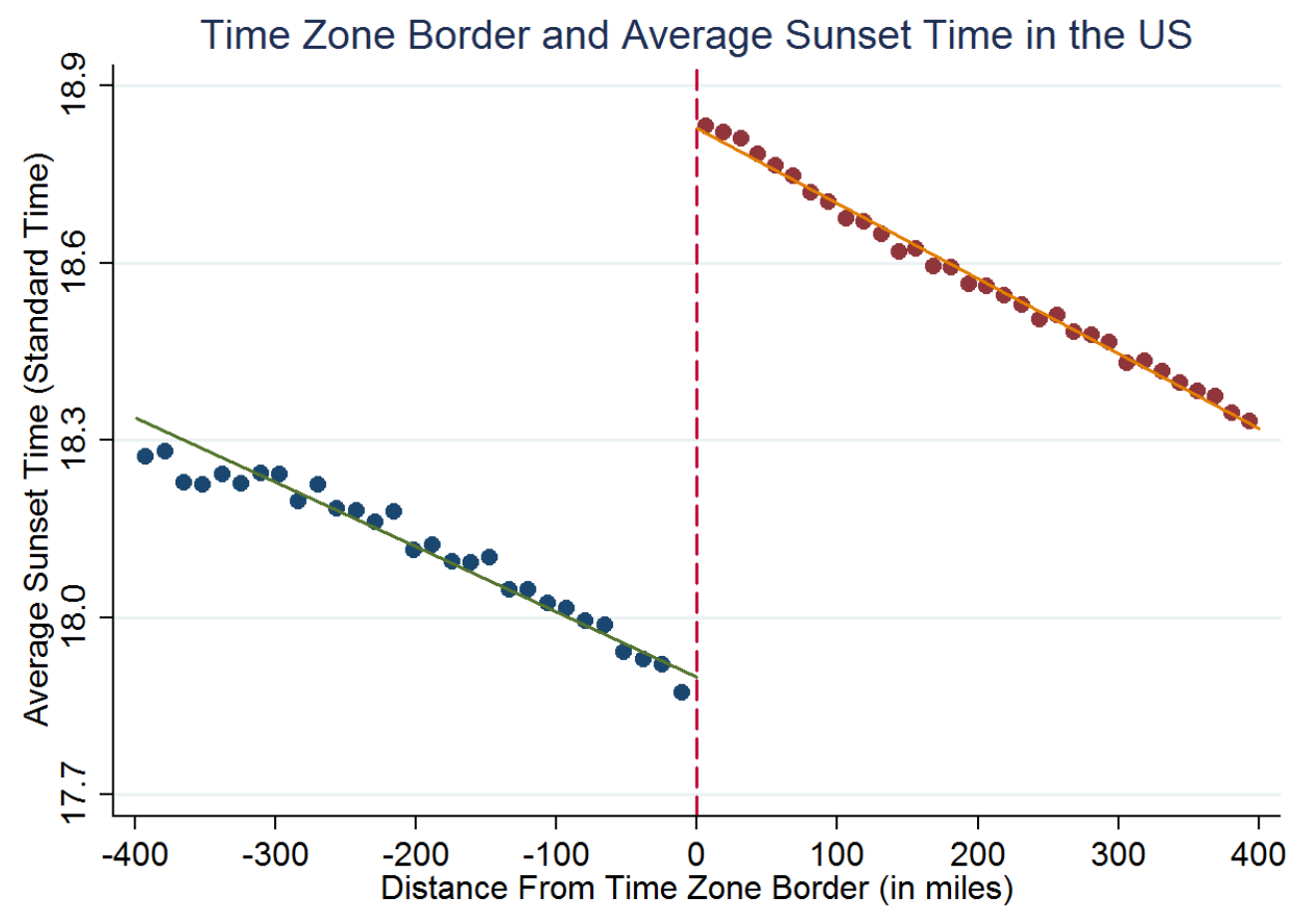

Figure 6: Sleep Duration over the Week

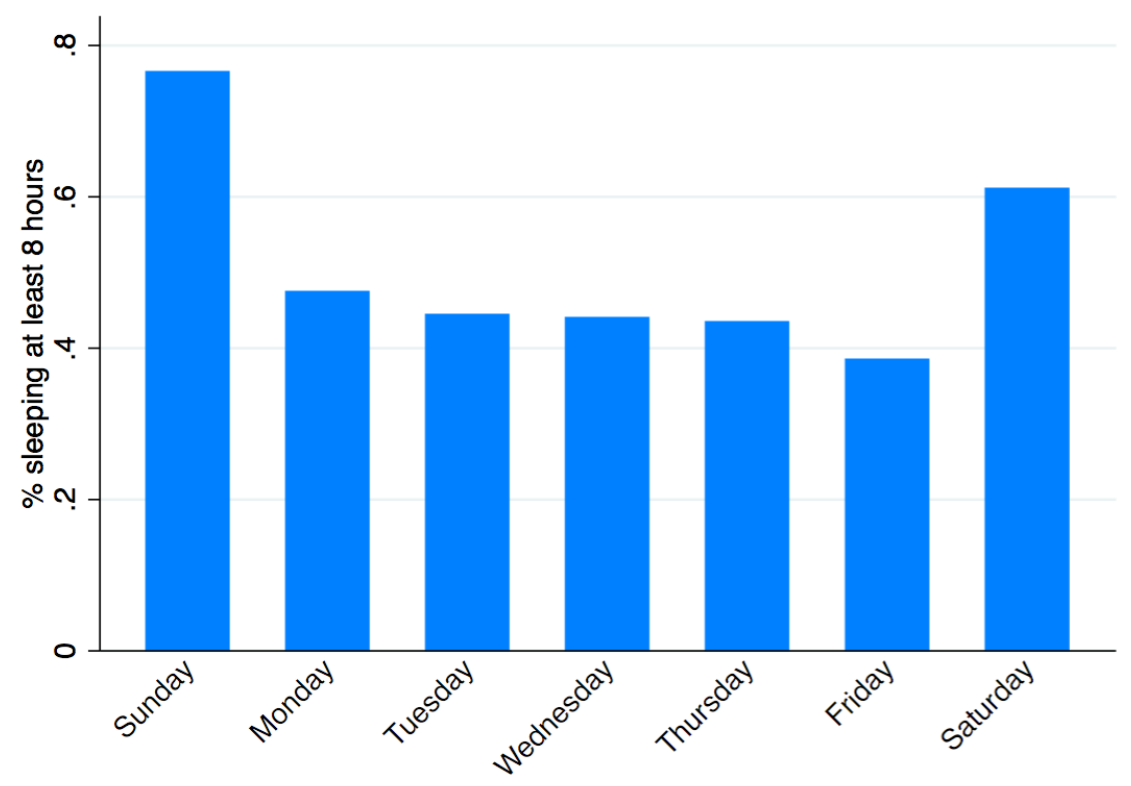


Figure 7: Discontinuity in Sleep Duration

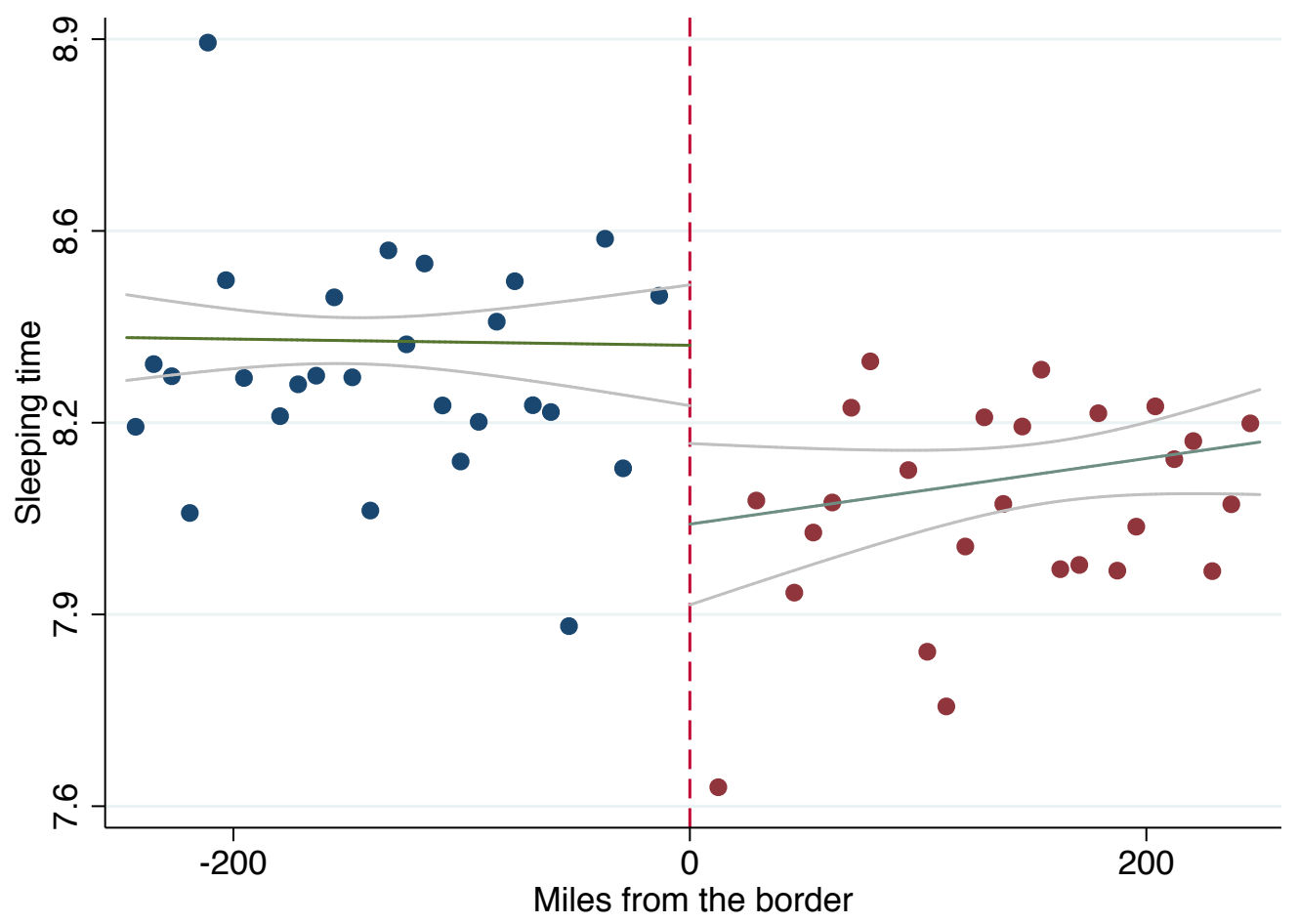

Notes - Data are drawn from the ATUS (2003-2013). 
Table 1: Balancing Test

\begin{tabular}{|c|c|c|c|c|}
\hline & $\begin{array}{l}\text { Early Sunset Border } \\
\text { Within } 250 \text { miles }\end{array}$ & $\begin{array}{l}\text { Late Sunset Border } \\
\text { Within } 250 \text { miles }\end{array}$ & $\begin{array}{c}\text { Counties at the border } \\
\text { Within } 250 \text { miles } \\
\text { Late-Early Sunset Side of Time Zone }\end{array}$ & Observations \\
\hline Average Sunset Time & $\begin{array}{l}18.007 \\
(0.970)\end{array}$ & $\begin{array}{l}18.588 \\
(0.909)\end{array}$ & $\begin{array}{c}0.572^{* * *} \\
(0.039)\end{array}$ & 16,557 \\
\hline Sleep Hours & $\begin{array}{c}8.382 \\
(1.921)\end{array}$ & $\begin{array}{c}8.188 \\
(1.965)\end{array}$ & $\begin{array}{l}-0.188^{* * *} \\
(0.051)\end{array}$ & 16,557 \\
\hline Sleep at least 8 hours & $\begin{array}{c}0.591 \\
(0.492)\end{array}$ & $\begin{array}{c}0.544 \\
(0.498)\end{array}$ & $\begin{array}{c}-0.046^{* * *} \\
(0.010)\end{array}$ & 16,557 \\
\hline Awake at $11 \mathrm{pm}$ & $\begin{array}{c}0.311 \\
(0.464)\end{array}$ & $\begin{array}{c}0.385 \\
(0.486)\end{array}$ & $\begin{array}{c}0.069^{* * *} \\
(0.016)\end{array}$ & 16,557 \\
\hline Awake at 7.30am & $\begin{array}{c}0.575 \\
(0.494)\end{array}$ & $\begin{array}{c}0.558 \\
(0.497)\end{array}$ & $\begin{array}{l}-0.017 \\
(0.017)\end{array}$ & 16,557 \\
\hline Obese & $\begin{array}{c}0.244 \\
(0.430)\end{array}$ & $\begin{array}{l}0.268 \\
(0.443)\end{array}$ & $\begin{array}{l}0.036^{* *} \\
(0.015)\end{array}$ & 4,331 \\
\hline Poor Health Status & $\begin{array}{c}0.099 \\
(0.298)\end{array}$ & $\begin{array}{c}0.081 \\
(0.273)\end{array}$ & $\begin{array}{l}-0.015 \\
(0.011)\end{array}$ & 9,696 \\
\hline Female & $\begin{array}{c}0.490 \\
(0.500)\end{array}$ & $\begin{array}{c}0.498 \\
(0.500)\end{array}$ & $\begin{array}{c}0.009 \\
(0.010)\end{array}$ & 16,557 \\
\hline Age & $\begin{array}{c}38.478 \\
(10.311)\end{array}$ & $\begin{array}{c}38.913 \\
(10.500)\end{array}$ & $\begin{array}{c}0.489 \\
(0.385)\end{array}$ & 16,557 \\
\hline Black & $\begin{array}{l}0.0481 \\
(0.214)\end{array}$ & $\begin{array}{l}0.0963 \\
(0.295)\end{array}$ & $\begin{array}{c}0.049^{* * *} \\
(0.016)\end{array}$ & 16,557 \\
\hline White & $\begin{array}{c}0.858 \\
(0.349)\end{array}$ & $\begin{array}{c}0.848 \\
(0.359)\end{array}$ & $\begin{array}{l}-0.010 \\
(0.021)\end{array}$ & 16,557 \\
\hline Holiday & $\begin{array}{c}0.018 \\
(0.133)\end{array}$ & $\begin{array}{c}0.018 \\
(0.133)\end{array}$ & $\begin{array}{l}-0.000 \\
(0.003)\end{array}$ & 16,557 \\
\hline Weekend & $\begin{array}{c}0.510 \\
(0.500)\end{array}$ & $\begin{array}{c}0.489 \\
(0.500)\end{array}$ & $\begin{array}{l}-0.018 \\
(0.016)\end{array}$ & 16,557 \\
\hline Less than High School & $\begin{array}{c}0.307 \\
(0.461)\end{array}$ & $\begin{array}{c}0.303 \\
(0.460)\end{array}$ & $\begin{array}{c}0.003 \\
(0.021)\end{array}$ & 16,557 \\
\hline Some College & $\begin{array}{c}0.309 \\
(0.462)\end{array}$ & $\begin{array}{c}0.316 \\
(0.465)\end{array}$ & $\begin{array}{c}0.009 \\
(0.014)\end{array}$ & 16,557 \\
\hline College or More & $\begin{array}{l}0.3836 \\
(0.486)\end{array}$ & $\begin{array}{c}0.380 \\
(0.486)\end{array}$ & $\begin{array}{l}-0.012 \\
(0.019)\end{array}$ & 16,557 \\
\hline Number of children & $\begin{array}{c}0.977 \\
(1.178)\end{array}$ & $\begin{array}{c}0.922 \\
(1.134)\end{array}$ & $\begin{array}{l}-0.046 \\
(0.033)\end{array}$ & 16,557 \\
\hline Married & $\begin{array}{c}0.587 \\
(0.492)\end{array}$ & $\begin{array}{c}0.596 \\
(0.490)\end{array}$ & $\begin{array}{c}0.009 \\
(0.019)\end{array}$ & 16,557 \\
\hline Weekly earnings & $\begin{array}{c}863.253 \\
(643.282)\end{array}$ & $\begin{array}{c}831.308 \\
(603.732)\end{array}$ & $\begin{array}{l}-31.513 \\
(24.246)\end{array}$ & 14,829 \\
\hline Hourly Wage & $\begin{array}{l}15.826 \\
(9.671)\end{array}$ & $\begin{array}{l}15.114 \\
(8.996)\end{array}$ & $\begin{array}{c}-0.602 \\
(0.446)\end{array}$ & 8,325 \\
\hline
\end{tabular}

Notes - Data are drawn from the ATUS (2003-2013). The sample is restricted to employed individuals aged 18-55. 
Table 2: Effect of Late Sunset Time on Sleeping (Only Employed)

\begin{tabular}{lcccc}
\hline \hline & $(1)$ & $(2)$ & $(3)$ & $(4)$ \\
Dep.Var.: & Sleep Hours & Sleep Hours & Sleep Hours & Sleep $\geq 8$ hours \\
\hline & & & & \\
Late Sunset Border & $-0.319^{* * *}$ & $-0.319^{* * *}$ & $-0.386^{* *}$ & $-0.082^{* * *}$ \\
& $(0.080)$ & $(0.119)$ & $(0.162)$ & $(0.021)$ \\
& & & & \\
Observations & 16,557 & 16,557 & 3,918 & 16,557 \\
Adj. $R^{2}$ & 0.132 & 0.132 & 0.129 & 0.090 \\
$F^{*}(1,63)$ & 15.84 & 7.16 & 5.71 & 15.69 \\
Mean of Dep.Var. & 8.040 & 8.040 & 8.040 & 0.517 \\
Std. Dev. & 1.784 & 1.790 & 1.80 & 0.484 \\
& & & & \\
\hline State FE & NO & YES & NO & NO \\
Bandwidth (miles) & 250 & 250 & 100 & 250 \\
\hline \hline
\end{tabular}

Notes - Data are drawn from the ATUS (2003-2013). All estimates include the distance to the time zone boundary and its interaction with the late sunset border, standard socio-demographic characteristics (age, race, sex, education, married and number of children), county characteristics (region, latitude and longitude and a dummy for large counties), interview characteristics (interview month and year, a dummy that controls for the application of DST, and two dummies that control for whether the interview was conducted during a public holiday or over the weekend). Significance levels: ${ }^{* *} p<0.01,{ }^{* *} p<0.05,{ }^{*} p<0.1$. Standard errors are robust and clustered at the geographical level (counties are grouped based on the distance from the time zone border).

${ }^{*}$ F-test on the significance of late sunset border. 
Table 3: Effect of Late Sunset Time on Sleeping (Employed vs. Unemployed)

\begin{tabular}{|c|c|c|c|c|c|c|}
\hline \multirow{3}{*}{$\begin{array}{l}\text { Dep.Var.: } \\
\text { Sample }\end{array}$} & (1) & (2) & (3) & $(4)$ & (5) & (6) \\
\hline & \multicolumn{2}{|c|}{ Sleep Hours } & \multicolumn{2}{|c|}{ Awake at $11 \mathrm{pm}$} & \multicolumn{2}{|c|}{ Awake at 7:30 am } \\
\hline & Employed & Unemployed & Employed & Unemployed & Employed & Unemployed \\
\hline Late Sunset Border & $\begin{array}{c}-0.319^{* * *} \\
(0.080)\end{array}$ & $\begin{array}{c}0.142 \\
(0.325)\end{array}$ & $\begin{array}{c}0.138^{* * *} \\
(0.031)\end{array}$ & $\begin{array}{l}0.129^{* *} \\
(0.066)\end{array}$ & $\begin{array}{l}-0.011 \\
(0.034)\end{array}$ & $\begin{array}{c}-0.134^{* *} \\
(0.055)\end{array}$ \\
\hline Observations & 16,557 & 2,082 & 16,557 & 2,082 & 16,557 & 2,082 \\
\hline Adj. $R^{2}$ & 0.132 & 0.040 & 0.047 & 0.082 & 0.193 & 0.128 \\
\hline Mean of Dep.Var. & 8.04 & 8.79 & 0.337 & 0.383 & 0.658 & 0.414 \\
\hline Std. Dev. & 1.965 & 2.023 & 0.498 & 0.491 & 0.4993 & 0.484 \\
\hline Bandwidth (miles) & 250 & 250 & 250 & 250 & 250 & 250 \\
\hline
\end{tabular}

Notes - Data are drawn from the ATUS (2003-2013). All estimates include the distance to the time zone boundary and its interaction with the late sunset border, standard socio-demographic characteristics (age, race, sex, education, married and number of children), county characteristics (region, latitude and longitude and a dummy for large counties), interview characteristics (interview month and year, a dummy that controls for the application of DST, and two dummies that control for whether the interview was conducted during a public holiday or over the weekend). Significance levels: ${ }^{* * *} p<0.01,{ }^{* *} p<0.05,{ }^{*} p<0.1$. Standard errors are robust and clustered at the geographical level (counties are grouped based on the distance from the time zone border). 
Table 4: Effect of late sunset time on sleeping by work start time

\begin{tabular}{|c|c|c|c|c|}
\hline Work start : & $\begin{array}{c}(1) \\
5-7 \mathrm{am}\end{array}$ & $\begin{array}{c}(2) \\
7.01-8.29 \mathrm{am} \\
\end{array}$ & $\begin{array}{c}(3) \\
8.30 \mathrm{am}-12 \mathrm{pm} \\
\end{array}$ & $\begin{array}{c}(4) \\
\text { 8.30am-12pm }\end{array}$ \\
\hline Late Sunset Border & $\begin{array}{c}-0.587^{* * *} \\
(.118)\end{array}$ & $\begin{array}{c}-0.304^{* *} \\
(.138)\end{array}$ & $\begin{array}{l}-0.031 \\
(.199)\end{array}$ & $\begin{array}{l}-0.023 \\
(.198)\end{array}$ \\
\hline $\begin{array}{l}\text { Late Sunset Border* } \\
\text { Leaving children at school before 8am }\end{array}$ & & & & $\begin{array}{l}-0.450^{*} \\
(0.260)\end{array}$ \\
\hline Leaving children at school before 8 am & & & & $\begin{array}{l}-0.356^{*} \\
(0.195)\end{array}$ \\
\hline Observations & 2,207 & 3,046 & 2,240 & 2,240 \\
\hline Adj. $R^{2}$ & 0.071 & 0.073 & 0.078 & 0.083 \\
\hline Mean of Dep. Var. & 7.148 & 7.698 & 8.230 & 8.230 \\
\hline Std. Dev. & 1.324 & 1.378 & 1.565 & 1.565 \\
\hline Bandwidth (miles) & 250 & 250 & 250 & 250 \\
\hline
\end{tabular}

Notes - Data are drawn from the ATUS (2003-2013). The sample is restricted to individuals who reported having worked on the day of the ATUS interview. All estimates also include the distance to the time zone boundary and its interaction with the late sunset border, standard socio-demographic characteristics (age, sex, education, married and number of children), county characteristics (region, latitude and longitude and a dummy for large counties), interview characteristics (interview month and year, a dummy that controls for the application of DST, and two dummies that control for whether the interview was conducted during a public holiday or over the weekend). Column (4) interacts the late sunset border dummy with a dummy for people who leave their children at school before $8 \mathrm{am}$. Significance levels: ${ }^{* * *} p<0.01,{ }^{* *} p<0.05,{ }^{*} p<0.1$. Standard errors are robust and clustered at the geographical level (counties are grouped based on the distance from the time zone border). 
Table 5: Heterogeneity Across Time Zone Border and Sweeps Weeks

\begin{tabular}{lccc}
\hline \hline & $(1)$ & $(2)$ & $(3)$ \\
& Sleep duration (ATUS) & Bedtime (Jawbone) & Sleep duration (ATUS) \\
\hline Late Sunset Border & $-0.262^{* * *}$ & $0.303^{* * *}$ & $-0.374^{* * *}$ \\
& $(0.088)$ & $(0.046)$ & $(0.082)$ \\
Late Sunset Border*CM & $-0.289^{* *}$ & -0.015 & \\
& $(0.114)$ & $(0.049)$ & \\
Late Sunset Border*MP & & & \\
& -0.085 & $-0.073^{* *}$ & \\
& $(0.091)$ & $(0.034)$ & 0.092 \\
Late Sunset Border*sweeps & & & $(0.067)$ \\
& & & $-0.103^{* * *}$ \\
Sweeps weeks & & & $(0.036)$ \\
& & & 16,653 \\
Observations & & & 0.136 \\
Adj. $R^{2}$ & & & 8.040 \\
Mean of Dep.Var. & 16,653 & 2,041 & 1.784 \\
Std. Dev. & 0.136 & 0.631 & \\
\hline \hline
\end{tabular}

Notes - Data are drawn from the ATUS (2003-2013). All estimates include the distance to the time zone boundary and its interaction with the late sunset border, latitude, longitude, census regions, and a dummy for large counties. Columns (1) and (3) also include the same socio-demographic and interview controls as in Table 2, while Column (2) includes socio-demographic characteristics at the county level (share of people over 65 , under 25 , female, white, black and with high school). Significance levels: ${ }^{* * *} p<0.01,{ }^{* *} p<$ $0.05,{ }^{*} p<0.1$. Standard errors are robust and clustered at the geographical level (counties are grouped based on the distance from the time zone border). 


\section{Table 6: Effect of Sleeping on Overweight, Obesity and Poor Health (Only Employed)}

\begin{tabular}{|c|c|c|c|c|c|c|}
\hline \multirow{3}{*}{ Dep.Var.: } & (1) & (2) & (3) & (4) & (5) & (6) \\
\hline & \multicolumn{2}{|c|}{ Overweight } & \multicolumn{2}{|l|}{ Obese } & \multicolumn{2}{|c|}{ Poor health } \\
\hline & Reduced form & IV & Reduced form & IV & Reduced form & IV \\
\hline \multirow[t]{2}{*}{ Late Sunset Border } & $0.065^{*}$ & & $0.063^{* *}$ & & $0.031^{* *}$ & \\
\hline & $(0.035)$ & & $(0.032)$ & & $(0.014)$ & \\
\hline \multirow[t]{2}{*}{ Sleep Hours } & & $-0.143^{*}$ & & $-0.139 * *$ & & $-0.085^{* * *}$ \\
\hline & & $(0.088)$ & & $(0.061)$ & & $(0.033)$ \\
\hline Observations & 4,122 & 4,122 & 4,122 & 4,122 & 9,177 & 9,177 \\
\hline$F^{*}(1,61)$ & & 11.72 & & 11.72 & & 17.96 \\
\hline Mean of Dep.Var. & 0.627 & 0.627 & 0.263 & 0.263 & 0.091 & 0.091 \\
\hline Std. Dev. & 0.483 & 0.483 & 0.440 & 0.440 & 0.287 & 0.287 \\
\hline Bandwidth (miles) & 250 & 250 & 250 & 250 & 250 & 250 \\
\hline
\end{tabular}

Notes - All estimates include the distance to the time zone boundary and its interaction with the late sunset border, standard sociodemographic characteristics (age, race, sex, education, married and number of children), county characteristics (region, latitude and longitude and a dummy for large counties), interview characteristics (interview month and year, a dummy that controls for the application of DST, and two dummies that control for whether the interview was conducted during a public holiday or over the weekend). We exclude from the estimates recent cohorts of immigrants (post 2005). Significance levels: ${ }^{* * *} p<0.01,{ }^{* *} p<0.05,{ }^{*} p<$ 0.1. Standard errors are robust and clustered at the geographical level (counties are grouped based on the distance from the time zone border). ${ }^{*} F$-test on the excluded instrument. 
Table 7: Heterogeneity by Age Group (Only Employed)

\begin{tabular}{lcccccc}
\hline \hline \multirow{2}{*}{ Dep.Var.: } & $\begin{array}{c}(1) \\
\text { Overweight }\end{array}$ & $\begin{array}{c}(3) \\
\text { Obese }\end{array}$ & \multicolumn{2}{c}{$\begin{array}{c}(4) \\
\text { Poor health }\end{array}$} \\
& age $<40$ & age $\geq 40$ & age $<40$ & age $\geq 40$ & age $<40$ & age $\geq 40$ \\
\hline Late Sunset Border & 0.047 & $0.091^{*}$ & 0.010 & $0.120^{* *}$ & 0.029 & $0.033^{*}$ \\
& $(0.055)$ & $(0.047)$ & $(0.043)$ & $(0.055)$ & $(0.019)$ & $(0.019)$ \\
$\mathrm{N}$ & & & & & & \\
Observations & 2,216 & 1,906 & 2,216 & 1,906 & 4,939 & 4,238 \\
Mean of Dep.Var. & 0.588 & 0.674 & 0.255 & 0.268 & 0.082 & 0.0100 \\
Std.Dev. & 0.469 & 0.437 & 0.436 & 0.443 & 0.275 & 0.300 \\
\hline Bandwidth (miles) & 250 & 250 & 250 & 250 & 250 & 250 \\
\hline
\end{tabular}

Notes - All estimates include the distance to the time zone boundary and its interaction with the late sunset border, standard sociodemographic characteristics (age, race, sex, education, married and number of children), county characteristics (region, latitude and longitude and a dummy for large counties), interview characteristics (interview month and year, a dummy that controls for the application of DST, and two dummies that control for whether the interview was conducted during a public holiday or over the weekend). We exclude from the estimates recent cohorts of immigrants (post 2005). Significance levels: ${ }^{* * *} p<0.01,{ }^{* *} p<0.05,{ }^{* *} p<$ 0.1. Standard errors are robust and clustered at the geographical level (counties are grouped based on the distance from the time zone border). 
Table 8: Sleep Duration and Cognitive Impairment

\begin{tabular}{lcccccc}
\hline \hline & $(1)$ & $\begin{array}{c}(2) \\
\text { Reduced-Form }\end{array}$ & $(3)$ & $(4)$ & $(5)$ & $(6)$ \\
& \multicolumn{7}{c}{ TS2SLS } \\
Late Sunset Border & $\begin{array}{c}0.004^{* * *} \\
(0.001)\end{array}$ & $\begin{array}{c}0.006^{* * *} \\
(0.002)\end{array}$ & $\begin{array}{c}0.004^{* * *} \\
(0.001)\end{array}$ & & & \\
Sleep Hours & & & & $-0.014^{* * *}$ & $-0.018^{* * *}$ & $-0.011^{* *}$ \\
& & & & $(0.003)$ & $(0.005)$ & $(0.004)$ \\
Bandwidth & 250 & 100 & 250 & 250 & 100 & 250 \\
State FE & $\mathrm{NO}$ & $\mathrm{NO}$ & $\mathrm{YES}$ & $\mathrm{NO}$ & $\mathrm{NO}$ & YES \\
& & & & & & \\
Observations & $1,447,115$ & 473,372 & $1,447,115$ & $1,447,115$ & 473,372 & $1,447,115$ \\
Mean of Dep. Var. & 0.0163 & 0.0152 & 0.0163 & 0.0163 & 0.0152 & 0.0163 \\
Std. Dev. & 0.127 & 0.122 & 0.127 & 0.127 & 0.122 & 0.127 \\
\hline
\end{tabular}

Notes - Data are drawn from the 2000 US CENSUS. All estimates include the distance to the time zone boundary and its interaction with the late sunset border, standard socio-demographic characteristics (age, race, sex, education, married and number of children), county characteristics (region, latitude and longitude and a dummy for large counties), interview characteristics (interview month and year and a dummy that controls for the application of DST). Significance levels: ${ }^{* * *} p<0.01,{ }^{* *} p<0.05,{ }^{*} p<0.1$. Standard errors are robust and clustered at the geographical level (counties are grouped based on the distance from the time zone border). 
Table 9: Time Zone Boundary and Late Meals

\begin{tabular}{lccccc}
\hline \hline Dep.Var.: & $\begin{array}{c}(1) \\
\text { Started meal } \\
\text { after 6pm }\end{array}$ & $\begin{array}{c}\text { Started meal } \\
\text { after 7pm }\end{array}$ & $\begin{array}{c}(3) \\
\text { Started meal } \\
\text { after 8pm }\end{array}$ & $\begin{array}{c}\text { Started meal } \\
\text { after 9pm }\end{array}$ & $\begin{array}{c}(5) \\
\text { Started meal } \\
\text { after 10pm }\end{array}$ \\
\hline Late Sunset Border & $\begin{array}{c}0.099^{* * *} \\
(0.024)\end{array}$ & $\begin{array}{c}0.066^{* * *} \\
(0.015)\end{array}$ & $\begin{array}{c}0.035^{* * *} \\
(0.012)\end{array}$ & $\begin{array}{c}0.011 \\
(0.009)\end{array}$ & $\begin{array}{c}0.009^{*} \\
(0.005)\end{array}$ \\
& YES & YES & YES & YES & YES \\
$\begin{array}{l}\text { Number of meals } \\
\text { before }\end{array}$ & & & & & \\
$\begin{array}{l}\text { Observations } \\
\text { Mean of Dep.Var. }\end{array}$ & 16,557 & 16,557 & 16,557 & 16,557 & 16,557 \\
Std. Dev. & 0.311 & 0.163 & 0.077 & 0.033 & 0.011 \\
\hline \hline
\end{tabular}

Notes - Data are drawn from the ATUS (2003-2013). All estimates include the distance to the time zone boundary and its interaction with the late sunset border, standard socio-demographic characteristics (age, race, sex, education, married and number of children), county characteristics (region, latitude and longitude and a dummy for large counties), interview characteristics (interview month and year, a dummy that controls for the application of DST, and two dummies that control for whether the interview was conducted during a public holiday or over the weekend), and dummies for the number of meals that occurred before $5 \mathrm{pm}$. Significance levels: ${ }^{* * *} p<0.01,{ }^{* *} p<0.05,{ }^{*} p<0.1$. Standard errors are robust and clustered at geographical level (counties are grouped based on the distance from the time zone border). 
Table 10: Time Zone Boundary and Dining Out

\begin{tabular}{|c|c|c|c|c|}
\hline Dependent Variable: & $\begin{array}{c}\text { (1) } \\
\text { Eating Out }\end{array}$ & $\begin{array}{c}(2) \\
\text { Eating Out }\end{array}$ & $\begin{array}{c}\text { (3) } \\
\text { Dinner Out }\end{array}$ & $\begin{array}{c}(4) \\
\text { Dinner Out }\end{array}$ \\
\hline Late Sunset Border & $\begin{array}{c}0.038 \\
(0.025)\end{array}$ & $\begin{array}{c}0.037 \\
(0.022)\end{array}$ & $\begin{array}{c}0.084^{* * *} \\
(0.017)\end{array}$ & $\begin{array}{c}0.084^{* * *} \\
(0.017)\end{array}$ \\
\hline $\begin{array}{l}\text { Number of meals } \\
\text { before } 5 \mathrm{pm}\end{array}$ & $\mathrm{NO}$ & YES & $\mathrm{NO}$ & YES \\
\hline Observations & 16,557 & 16,557 & 16,557 & 16,557 \\
\hline Mean of Dep. Var. & 0.550 & 0.550 & 0.312 & 0.312 \\
\hline Std.Dev. & 0.498 & 0.498 & 0.463 & 0.463 \\
\hline
\end{tabular}

Notes - Data are drawn from the ATUS (2003-2013). The dependent variable in columns 1 and 2 is an indicator for whether an individual consumed a meal out (including lunch), while in columns 3 and 4, the dependent variable is an indicator for whether an individual consumed a meal out after $5 \mathrm{pm}$ (dinner time). All estimates include the distance to the time zone boundary and its interaction with the late sunset border, standard socio-demographic characteristics (age, race, sex, education, married and number of children), county characteristics (region, latitude and longitude and a dummy for large counties), interview characteristics (interview month and year, a dummy that controls for the application of DST, and two dummies that control for whether the interview was conducted during a public holiday or over the weekend). Significance levels: ${ }^{* * *} p<0.01,{ }^{* *} p<0.05,{ }^{*} p<0.1$. Standard errors are robust and clustered at the geographical level (counties are grouped based on the distance from the time zone border). 
Table 11: Time Zone Border and Physical Activity (More than 30 Minutes Vigorous or Moderate), ATUS

\begin{tabular}{lccc}
\hline \hline Dep.Var. & $\begin{array}{c}(1) \\
\text { Physically Active } \\
\text { All }\end{array}$ & $\begin{array}{c}(2) \\
\text { Physically Active } \\
\text { Child } \leq 13\end{array}$ & $\begin{array}{c}(3) \\
\text { Physically Active } \\
\text { No Child } \leq 13\end{array}$ \\
\hline Late Sunset Border & -0.024 & $-0.052^{* *}$ & -0.007 \\
& $(0.016)$ & $(0.022)$ & $(0.023)$ \\
Observations & & & \\
Mean of Dep.Var. & 16,557 & 7,452 & 9,105 \\
Std. Dev. & 0.385 & 0.474 & 0.311 \\
\hline \hline
\end{tabular}

Notes - Data are drawn from the ATUS (2003-2013). The dependent variable is the an indicator for whether individuals conducted at least 30 minutes of moderate/vigorous activity in the day preceding the interview based on metabolic equivalents associated with individual activities reported in the ATUS (Tudor et al., 2009). All estimates include the distance to the time zone boundary and its interaction with the late sunset border, standard socio-demographic characteristics (age, race, sex, education, married and number of children), county characteristics (region, latitude and longitude and a dummy for large counties), interview characteristics (interview month and year, a dummy that controls for the application of DST, and two dummies that control for whether the interview was conducted during a public holiday or over the weekend). Significance levels: ${ }^{* * *} p<0.01,{ }^{* *} p<0.05,{ }^{*} p<0.1$. Standard errors are robust and clustered at the geographical level (counties are grouped based on the distance from the time zone border). 
Table 12: Time Zone Border and Physical Activity at County Level (BRFSS, 150 Minutes of Moderate Physical Activity per Week)

\begin{tabular}{lccc}
\hline \hline & $(1)$ & $(2)$ & $(3)$ \\
Dep.Var. & Physically Active $(\%)$ & Physically Active (\%) & Physically Active (\%) \\
\hline Late Sunset Border & $-1.031^{* * *}$ & $-1.547^{* * *}$ & $-1.408^{* * *}$ \\
& $(0.372)$ & $(0.438)$ & $(0.452)$ \\
& & & $1.392^{* * *}$ \\
Late Sunset Border*high unemployment & & $(.455)$ & $0.812^{* *}$ \\
& & & $(0.414)$ \\
Late Sunset Border*high share65+ & & & 2,031 \\
& & & 0.547 \\
Observations & & 2,031 & 51.371 \\
Adj. $R^{2}$ & 2,031 & 0.568 & 6.556 \\
Mean of Dep.Var. & 0.537 & 51.371 & 6.556 \\
Std. Dev. & 51.371 & & \\
\hline \hline
\end{tabular}

Notes - The dependent variable is the share of people in the county who, in 2011, reported a sufficient level of physical activity according to the BFRSS definition (at least 150 minutes of moderate physical activity per week). All estimates include the distance to the time zone boundary and its interaction with the late sunset border, socio-demographic characteristics at the county level (share of people over 65, under 25, female, white, black and with high school), latitude, longitude, census regions, and a dummy for large counties. The second specification adds a dummy for counties with an unemployment rate higher than the median and its interaction with the right border (late sunset time). The third specification adds to the first a dummy for counties with a share of people over 65 higher than the median and its interaction with the right border (late sunset time). Significance levels: ${ }^{* * *} p<0.01$, ${ }^{* *} p<0.05,{ }^{*} p<0.1$. Standard errors are robust and clustered at the geographical level (counties are grouped based on the distance from the time zone border). 


\section{Appendix A - For Online Pubblication}

Table A.1: Effect of Late Sunset Time on Sleeping (Only Employed)

\begin{tabular}{|c|c|c|c|c|c|c|}
\hline Dep.Var.: & $\begin{array}{c}\text { (1) } \\
\text { Sleep Hours } \\
\text { (naps excluded) }\end{array}$ & $\begin{array}{c}\text { (2) } \\
\text { Sleep Hours } \\
\text { (naps included) }\end{array}$ & $\begin{array}{c}(3) \\
\text { Sleep } \leq 6 h \\
\text { (naps excluded) }\end{array}$ & $\begin{array}{c}(4) \\
\text { Sleep } \geq 8 h \\
\text { (naps excluded) }\end{array}$ & $\begin{array}{c}\text { (5) } \\
\text { Sleep } \in[8 h, 9 h]) \\
(\text { naps excluded) }\end{array}$ & $\begin{array}{c}(6) \\
\text { Naps }\end{array}$ \\
\hline Late Sunset Border & $\begin{array}{c}-0.318^{* * *} \\
(0.079)\end{array}$ & $\begin{array}{c}-0.298^{* * *} \\
(0.101)\end{array}$ & $\begin{array}{c}0.041^{* * *} \\
(0.012)\end{array}$ & $\begin{array}{c}-0.082^{* * *} \\
(0.021)\end{array}$ & $\begin{array}{l}-0.032^{*} \\
(0.017)\end{array}$ & $\begin{array}{c}0.021 \\
(0.047)\end{array}$ \\
\hline Observations & 16,557 & 16,675 & 16,557 & 16,557 & 16,557 & 16,675 \\
\hline Mean of Dep. Var. & 8.284 & 8.553 & 0.112 & 0.570 & 0.232 & 0.326 \\
\hline Std. Dev. & 1.965 & 2.127 & 0.315 & 0.495 & 0.422 & 1.012 \\
\hline
\end{tabular}

Notes - Data are drawn from the ATUS (2003-2013). All estimates include the distance to the time zone boundary and its interaction with the late sunset border, standard socio-demographic characteristics (age, race, sex, education, married and number of children), county characteristics (region, latitude and longitude and a dummy for large counties), interview characteristics (interview month and year, a dummy that controls for the application of DST, and two dummies that control for whether the interview was conducted during a public holiday or over the weekend). Significance levels: ${ }^{* * *} p<0.01,{ }^{* *} p<0.05,{ }^{*} p<0.1$. Standard errors are robust and clustered at the geographical level (counties are grouped based on the distance from the time zone border). 
Table A.2: Effect of Late Sunset Time on Sleeping by Sector

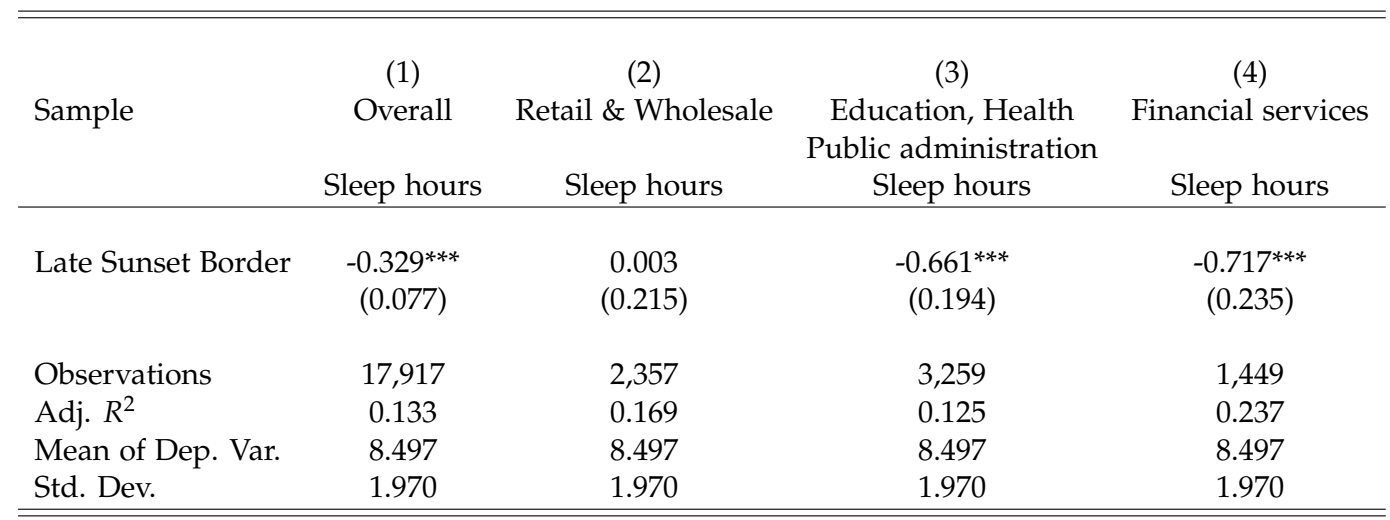

Notes - Data are drawn from the ATUS (2003-2013). All estimates include the distance to the time zone boundary and its interaction with the late sunset border, standard socio-demographic characteristics (age, race, sex, education, married and number of children), county characteristics (region, latitude and longitude and a dummy for large counties), interview characteristics (interview month and year, a dummy that controls for the application of DST, and two dummies that control for whether the interview was conducted during a public holiday or over the weekend). The second specification adds a dummy for counties with an unemployment rate higher than the median and its interaction with the right border (late sunset time). The third specification adds to the first specification a dummy for counties with a share of people over 65 higher than the median and its interaction with the right border (late sunset time). Significance levels: ${ }^{* *} p<0.01,{ }^{* *} p<0.05,{ }^{*} p<0.1$. Standard errors are robust and clustered at the geographical level (counties are grouped based on the distance from the time zone border).

Table A.3: Effect of Late Sunset Time on Sleeping by Household Composition

\begin{tabular}{lcccc}
\hline \hline & $(1)$ & $(2)$ & $(3)$ & $(4)$ \\
Sample: & \multicolumn{2}{c}{ All } & \multicolumn{2}{c}{ Employed } \\
\hline Child (age $\leq 13)$ in HH: & YES & NO & YES & NO \\
\hline Late Sunset Border & $-0.247^{* *}$ & -0.157 & $-0.436^{* * *}$ & $-0.263^{* *}$ \\
& $(.098)$ & $(.110)$ & $(.106)$ & $(.114)$ \\
& & & & \\
Observations & 10,393 & 11,923 & 7,511 & 9,046 \\
Adj. $R^{2}$ & .128 & .108 & .139 & .131 \\
Mean of Dep.Var. & 8.237 & 8.248 & 8.030 & 8.040 \\
Std. Dev. & 1.903 & 2.0905 & 1.870 & 2.040 \\
\hline Bandwidth (miles) & 250 & 250 & 250 & 250 \\
\hline \hline
\end{tabular}

Notes - Data are drawn from the ATUS (2003-2013). All estimates include the distance to the time zone boundary and its interaction with the late sunset border, standard socio-demographic characteristics (age, race, sex, education, married and number of children), county characteristics (region, latitude and longitude and a dummy for large counties), interview characteristics (interview month and year, a dummy that controls for the application of DST, and two dummies that control for whether the interview was conducted during a public holiday or over the weekend). Significance levels: ${ }^{* * *} p<0.01,{ }^{* *} p<0.05,{ }^{*} p<0.1$. Standard errors are robust and clustered at the geographical level (counties are grouped based on the distance from the time zone border). 
Table A.4: Reduced Form Effects by Schedule

\begin{tabular}{|c|c|c|c|}
\hline Work start : & $\begin{array}{c}(1) \\
5-7 \mathrm{am}\end{array}$ & $\begin{array}{c}(2) \\
7.01-8.29 \mathrm{am}\end{array}$ & $\begin{array}{c}(3) \\
8.30 \mathrm{am}-12 \mathrm{pm}\end{array}$ \\
\hline & \multicolumn{3}{|c|}{ Overweight } \\
\hline Late Sunset Border & $\begin{array}{c}0.214^{* * *} \\
(0.065)\end{array}$ & $\begin{array}{c}0.066 \\
(0.089)\end{array}$ & $\begin{array}{l}-0.189 \\
(0.144)\end{array}$ \\
\hline $\begin{array}{l}\text { Observations } \\
\text { Mean of Dep.Var. } \\
\text { Std.Dev. }\end{array}$ & $\begin{array}{c}725 \\
0.701 \\
0.457\end{array}$ & $\begin{array}{c}740 \\
0.581 \\
0.489\end{array}$ & $\begin{array}{c}571 \\
0.576 \\
0.495\end{array}$ \\
\hline & \multicolumn{3}{|c|}{ Obese } \\
\hline Late Sunset Border & $\begin{array}{c}0.172^{* *} \\
(.089)\end{array}$ & $\begin{array}{l}0.081 \\
(.099)\end{array}$ & $\begin{array}{l}-0.054 \\
(.130)\end{array}$ \\
\hline $\begin{array}{l}\text { Observations } \\
\text { Mean of Dep.Var. } \\
\text { Std.Dev. }\end{array}$ & $\begin{array}{c}725 \\
0.279 \\
0.457\end{array}$ & $\begin{array}{c}740 \\
0.231 \\
0.422\end{array}$ & $\begin{array}{c}571 \\
0.251 \\
0.434\end{array}$ \\
\hline & \multicolumn{3}{|c|}{ Poor health } \\
\hline Late Sunset Border & $\begin{array}{c}0.032 \\
(0.031)\end{array}$ & $\begin{array}{c}0.015 \\
(0.037)\end{array}$ & $\begin{array}{c}0.015 \\
(0.044)\end{array}$ \\
\hline Observations & 1,590 & 1,678 & 1,202 \\
\hline Mean of Dep.Var. & 0.085 & 0.085 & 0.089 \\
\hline Std.Dev. & 0.302 & 0.278 & 0.283 \\
\hline Bandwidth (miles) & 250 & 250 & 250 \\
\hline
\end{tabular}

Notes - The sample is restricted to individuals who reported having worked on the day of the ATUS interview. All estimates include the distance to the time zone boundary and its interaction with the late sunset border, standard socio-demographic characteristics (age, race, sex, education, married and number of children), county characteristics (region, latitude and longitude and a dummy for large counties), interview characteristics (interview month and year, a dummy that controls for the application of DST, and two dummies that control for whether the interview was conducted during a public holiday or over the weekend). We exclude from the estimates recent cohorts of immigrants (post 2005). Significance levels: ${ }^{* * *} p<0.01,{ }^{* *} p<0.05,{ }^{*} p<0.1$. Standard errors are robust and clustered at the geographical level (counties are grouped based on the distance from the time zone border). ${ }^{*} F$-test on the excluded instrument. 
Table A.5: Determinants of Sleep Duration

\begin{tabular}{|c|c|c|c|}
\hline Sample: & $\begin{array}{l}(1) \\
\text { All }\end{array}$ & $\begin{array}{c}(2) \\
\text { Working on } \\
\text { interview day }\end{array}$ & $\begin{array}{c}\text { (3) } \\
\text { Not working on } \\
\text { interview day }\end{array}$ \\
\hline weekend & $\begin{array}{c}1.120^{* * *} \\
(0.016)\end{array}$ & $\begin{array}{c}0.160^{* * *} \\
(0.029)\end{array}$ & $\begin{array}{c}0.484^{* * *} \\
(0.023)\end{array}$ \\
\hline female & $\begin{array}{c}0.213^{* * *} \\
(0.016)\end{array}$ & $\begin{array}{c}0.017 \\
(0.020)\end{array}$ & $\begin{array}{c}0.027 \\
(0.021)\end{array}$ \\
\hline age $25-30$ & $\begin{array}{c}-0.041 \\
(0.034)\end{array}$ & $\begin{array}{c}0.016 \\
(0.044)\end{array}$ & $\begin{array}{c}0.059 \\
(0.039)\end{array}$ \\
\hline age $30-39$ & $\begin{array}{c}-0.236^{* * *} \\
(0.031)\end{array}$ & $\begin{array}{l}-0.031 \\
(0.041)\end{array}$ & $\begin{array}{c}-0.160^{* * *} \\
(0.035)\end{array}$ \\
\hline age $40-49$ & $\begin{array}{c}-0.394^{* * *} \\
(0.033)\end{array}$ & $\begin{array}{c}-0.108^{* *} \\
(0.043)\end{array}$ & $\begin{array}{c}-0.345^{* * *} \\
(0.036)\end{array}$ \\
\hline age $50-55$ & $\begin{array}{c}-0.521^{* * *} \\
(0.035)\end{array}$ & $\begin{array}{c}-0.116^{* *} \\
(0.046)\end{array}$ & $\begin{array}{c}-0.554^{* * *} \\
(0.039)\end{array}$ \\
\hline black & $\begin{array}{c}-0.194^{* * *} \\
(0.039)\end{array}$ & $\begin{array}{c}-0.207^{* * *} \\
(0.049)\end{array}$ & $\begin{array}{c}0.039 \\
(0.045)\end{array}$ \\
\hline high-school dropout & $\begin{array}{c}0.374^{* * *} \\
(0.037)\end{array}$ & $\begin{array}{c}0.361^{* * *} \\
(0.043)\end{array}$ & $\begin{array}{c}0.302^{* * *} \\
(0.038)\end{array}$ \\
\hline some college & $\begin{array}{c}-0.105^{* * *} \\
(0.023)\end{array}$ & $\begin{array}{c}-0.167^{* * *} \\
(.028)\end{array}$ & $\begin{array}{c}-0.203^{* * *} \\
(.028)\end{array}$ \\
\hline college degree or more & $\begin{array}{c}-0.126^{* * *} \\
(0.021)\end{array}$ & $\begin{array}{c}-0.200^{* * *} \\
(0.026)\end{array}$ & $\begin{array}{c}-0.424^{* * *} \\
(0.026)\end{array}$ \\
\hline start work before 7am & & $\begin{array}{l}-.622^{* * *} \\
(0.023)\end{array}$ & \\
\hline start work after 8.30am & & $\begin{array}{c}0.576^{* * *} \\
(0.025)\end{array}$ & \\
\hline $\begin{array}{l}\text { leave children at school } \\
\text { before } 8 \mathrm{am}\end{array}$ & & $\begin{array}{c}-0.219^{* * *} \\
(0.029)\end{array}$ & $\begin{array}{c}-0.794^{* * *} \\
(0.051)\end{array}$ \\
\hline Constant & $\begin{array}{l}7.168^{* * *} \\
(0.150)\end{array}$ & $\begin{array}{l}6.808^{* * *} \\
(0.176)\end{array}$ & $\begin{array}{c}8.333^{* * *} \\
(0.183)\end{array}$ \\
\hline Observations & 76,785 & 32,277 & 53,490 \\
\hline Adj. $R^{2}$ & 0.105 & 0.111 & 0.047 \\
\hline Mean of Dep.Var. & 8.00 & 7.65 & 9.01 \\
\hline Std. Dev. & 1.77 & 1.52 & 1.95 \\
\hline
\end{tabular}

Notes - Data are drawn from ATUS (2003-2013). The estimates indicate the marginal difference with respect to a white male individual interviewed on a weekday with a high-school degree, starting work between 7am and 8.30am and not having to leave children at school before 8am. Column 1 focuses on our preferred sample of employed individuals aged between 18 and 55 . Column 2 restricts the analysis to individuals who reported to work on the day of the interview. Column 3 restricts the sample to individuals who did not work on the day of the interview (including non-employed). Significance levels: ${ }^{* * *} p<0.01,{ }^{* *} p<0.05,{ }^{*} p<0.10$. Robust standard errors are reported in parentheses. 
Table A.6: Unconfoundness Tests: Discontinuities in Height and Historical Literacy

\begin{tabular}{lcc}
\hline \hline & $(1)$ & $(2)$ \\
Variable: & Height (in cm) & Literacy in 1900 \\
\hline & & \\
Late Sunset Border & 0.161 & 0.013 \\
& $(0.521)$ & $(0.016)$ \\
& & \\
Observations & 4,614 & 18,381 \\
Adj. $R^{2}$ & 0.079 & 0.146 \\
Mean of Dep.Var. & 170.964 & 0.877 \\
Std. Dev. & 10.461 & 0.315 \\
\hline \hline
\end{tabular}

Notes - The first column tests for the presence of discontinuities in height using the same specification and sample as in Table 2, column 1. The second column tests for the presence of discontinuities in literacy using the 1900 census and controlling for standard socio-demographic characteristics (age, race, sex, married and number of children) and county characteristics (region fixed effects, latitude and longitude and a dummy for large counties). Significance levels: ${ }^{* *} p<0.01,{ }^{* *} p<0.05,{ }^{*} p<0.1$. Standard errors are robust and clustered at the geographical level (counties are grouped based on the distance from the time zone border). 
Table A.7: Residential Sorting Tests

\begin{tabular}{lcccc}
\hline \hline & $(1)$ & $(2)$ & $(3)$ & $(4)$ \\
& $\log ($ House value) & $\log$ (monthly rent) & $\begin{array}{c}\text { commuting time } \\
\text { (minutes) }\end{array}$ & $\begin{array}{c}\text { pop. density } \\
\text { (per sq.mile) }\end{array}$ \\
\hline Late Sunset Border & 0.041 & 0.044 & 0.400 & -7.437 \\
& $(0.035)$ & $(0.029)$ & $(0.0383)$ & $(33.052)$ \\
Observations & 2,041 & 2,041 & 2,041 & 2,041 \\
Adj. $R^{2}$ & 0.353 & 0.187 & 0.390 & 0.088 \\
Mean of Dep. Var. & 11.597 & 6.325 & 22.273 & 128.172 \\
Std. Dev. & 0.394 & 0.306 & 5.201 & 354.381 \\
\hline \hline
\end{tabular}

Notes - Data are drawn from the ACS (2009-2013). All estimates also include the distance to the time zone boundary and its interaction with the late sunset border, standard socio-demographic characteristics (age, sex, education, married and number of children), county characteristics (region, latitude and longitude and a dummy for large counties), interview characteristics (interview month and year and a dummy that controls for the application of DST. Significance levels: ${ }^{* *} p<0.01,{ }^{* *} p<0.05,{ }^{*} p<0.1$. Standard errors are robust and clustered at the geographical level (counties are grouped based on the distance from the time zone border). 
Table A.8: Sleeping and Time-Zone Border, by MSA size

\begin{tabular}{lccc}
\hline \hline Dep.Var.: & $\begin{array}{c}(1) \\
\text { Sleep Hours } \\
\text { Overall Sample }\end{array}$ & $\begin{array}{c}\text { Sleep Hours } \\
\text { Fewer than 500,000 } \\
\text { MSA residents }\end{array}$ & $\begin{array}{c}(3) \\
\text { Sleep Hours } \\
\text { More than 500,000 } \\
\text { MSA residents }\end{array}$ \\
\hline Late Sunset Border & $-0.318^{* * *}$ & $-0.216^{*}$ & $-0.422^{* * *}$ \\
& $(0.079)$ & $(0.123)$ & $(0.085)$ \\
Observations & 16,557 & 4,394 & 12,163 \\
Adj. $R^{2}$ & 0.137 & 0.156 & 0.139 \\
Mean of Dep. Var. & 8.284 & 8.186 & 8.319 \\
Std. Dev. & 1.965 & 1.898 & 1.988 \\
\hline \hline
\end{tabular}

Notes - Data are drawn from the ATUS (2003-2013). All estimates include the distance to the time zone boundary and its interaction with the late sunset border, standard socio-demographic characteristics (age, race, sex, education, married and number of children), county characteristics (region, latitude and longitude and a dummy for large counties), interview characteristics (interview month and year, a dummy that controls for the application of DST, and two dummies that control for whether the interview was during a public holiday or over the weekend). The second specification adds a dummy for counties with an unemployment rate higher than the median and its interaction with the right border (late sunset time). The third specification adds to the first specification a dummy for counties with a share of people over 65 higher than the median and its interaction with the right border (late sunset time). Significance levels: ${ }^{* *} p<0.01,{ }^{* *} p<0.05,{ }^{*} p<0.1$. Standard errors are robust and clustered at the geographical level (counties are grouped based on the distance from the time zone border). 